\title{
RELACIONES ENTRE FILOSOFÍA DEL DERECHO, CIENCIA JURÍDICA Y TEORÍA DEL DERECHO*
}

\author{
RELATIONS AMONG PHILOSOPHY OF LAW, \\ LEGAL SCIENCE AND LEGAL THEORY
}
RELATIONS ENTRE PHILOSOPHIE DU DROIT, DE LA SCIENCE JURIDIQUE ET DE THÉORIE JURIDIQUE

Gabriel Celis Danzinger**

\begin{abstract}
RESUMeN
El presente trabajo nos introduce al estudio del Derecho como objeto. Particularmente, acerca de la Filosofía, Jurisprudencia y Teoría del Derecho. Su historia, características y sus conexiones. Finalmente, el artículo propone algunos aportes de estas disciplinas para la práctica judicial.
\end{abstract}

\begin{abstract}
This work studies the Law as an object, particularly from Philosophy, Jurisprudence and Legal Theory perspectives. It also studies its history, characteristics, and connections. Finally, the article proposes some contributions from these disciplines to judicial practice.
\end{abstract}

\section{RÉSUMÉ}

Ce travail étude le Droit comme un objet, en particulier dans une perspective Philosophique, Jurisprudencielle et de Théorie Juridique. Il étude aussi son histoire, ses caractéristiques, et ses connexions. Enfin, l'article propose quelques contributions de ces disciplines à la pratique judiciaire.

\section{Palabras Claves:}

Filosofía del Derecho - Ciencia Jurídica - Teoría del Derecho

* El artículo fue recepcionado el 16 de julio de 2011, y aprobado para su publicación el 24 de noviembre de 2011.

** Abogado. Postítulo en Derecho Constitucional por la Universidad de Salamanca. Magíster en Derecho con mención en Derecho Público por la Universidad de Chile. Profesor titular de Derecho Administrativo Universidad de las Américas y Universidad Miguel de Cervantes. Profesor de Postgrado en las Universidades Finis Terrae, Católica Silva Henríquez y Viña del Mar. 
Key Words:

Philosophy of Law - Legal Science - Legal Theory

Mots Clé:

Philosophie de Droit- Science Juridique - Théorie de Droit 


\section{LA GRADACIÓN DEL CONOCIMIENTO JURÍDICO}

En términos generales es posible afirmar la existencia de diversos niveles racionales y sistemáticos de desarrollo en el conocimiento, los cuales son: la Filosofía, la Ciencia y la Técnica. Dicha gradación del saber se reproduce también en el ámbito del conocimiento jurídico, donde a su vez es posible distinguir tres eslabones: la Filosofía Jurídica, la Jurisprudencia Científica o Ciencia del Derecho, y la Técnica Jurídica.

Todas estas disciplinas constituyen saberes referidos al fenómeno jurídico, la Filosofía del Derecho como saber filosófico, la Jurisprudencia como saber científico y la Técnica Jurídica como conocimiento técnico. Quien se ocupa de la primera es el filósofo del Derecho, aquel que estudia la Ciencia del Derecho es el jurista teórico, y quien se aboca al ejercicio forense, es decir, a la práctica del ordenamiento normativo con el correspondiente desarrollo de destrezas y habilidades propias de la Técnica Jurídica, es el operador jurídico o jurista práctico, esto es, quien aplica o lleva a la praxis el Derecho positivo.

Este breve trabajo pretende centrarse exclusivamente en las relaciones que se dan entre la Filosofía Jurídica y la Ciencia del Derecho, a la cual debe sumarse la Teoría del Derecho, que como veremos, suele agruparse como rama de uno o de otro de estos saberes.

\section{La Filosofía Jurídica}

Desde un punto de vista epistemológico, la reflexión sobre el objeto y métodos de las Ciencias Jurídicas - que es lo que aquí se intenta -, constituye un tema propio de la teoría del conocimiento jurídico, que a su vez, integra el campo de estudio de la Filosofía del Derecho'.

En segundo lugar, y al igual como aconteció con la Filosofía general y las ciencias particulares, el precedente histórico de la Jurisprudencia se encuentra en la Filosofía Jurídica, siendo en la época de los juristas romanos cuando la Ciencia del Derecho comienza a independizarse del conocimiento filosófico.

En resumen, para describir los rasgos centrales de las Ciencias Jurídicas, se necesita una aproximación previa a la Filosofía del Derecho, que constituye su basamento histórico y epistemológico. Revisemos entonces, las principales peculiaridades de este saber filosófico sobre el fenómeno jurídico.

1 En tal sentido véase Calsamiglia, Albert. Introducción a la Ciencia Jurídica. $2^{a}$ Edición. Barcelona: Editorial Ariel, 1988, p. 12; y Aftalión, Enrique; Vilanova, José y Raffo, Julio. Introducción al Derecho. $3^{\mathrm{a}}$ Edición. Buenos Aires: Editorial AbeledoPerrot, 1988, p. 165. 
A grandes rasgos la historia de la Filosofía del Derecho corresponde a la evolución del pensamiento jurídico, es decir, a la historia de la Filosofía en lo que respecta a la reflexión sobre el fenómeno del Derecho ${ }^{2}$.

Los inicios más remotos de la Filosofía Jurídica en el sentido de actividad o actitud filosófica sobre el Derecho se encuentran en la Antigüedad. Ya en la cultura hebrea es posible constatar pensamientos bien definidos sobre el fenómeno jurídico. El Antiguo Testamento es una fuente rica en preceptos y reflexiones vinculadas al mundo normativo, que permiten entender su concepción sobre el Derecho y la sociedad, que será asimilada por los griegos, y luego a través de estos también por los romanos.

La proliferación de escuelas filosóficas durante el apogeo griego es enorme. Encontramos una variada cantidad de corrientes que se inicia en el siglo VII a.C., con los presocráticos (Heráclito, Parménides, etc.), para dar paso a los sofistas (s. V a.C), que inauguran el pensamiento subjetivista, siendo los más destacados Protágoras (480-410 a.C.), Pitágoras e Hipias.

En el período griego clásico se encuentra la filosofía ática de corte objetivista, desarrollada primero por Sócrates (446-399 a.C.); luego por Platón (427-347 a.C.) y su idealismo axiológico; y más tarde por Aristóteles, con el realismo ontológico (384-322 a.C.).

Un gran aporte al pensamiento jurídico antiguo lo debemos a San Pablo de Tarso (67 d.C.), quien formado en el Derecho Romano, la Filosofía griega y la escuela Judea hebraica, desarrolló una compleja estratificación de las leyes y teoría de la interpretación jurídica.

El extenso período comprendido en el medioevo también resulta bastante fructífero para la Filosofía Jurídica con las obras de San Agustín de Hipona (354-430), que origina la patrística, de orientación platónica; y Santo Tomás de Aquino (1225-1274), quien inaugura el pensamiento escolástico de base aristotélica. También habría que recordar en este contexto histórico a los nominalistas, Juan Duns Scoto (1266-1308) y Guillermo de Ockam (1300-1350 aprox.), quienes retoman la tendencia al subjetivismo.

Ahora bien, como disciplina independiente, o mejor dicho, en cuanto conocimiento sistemático y autónomo sobre el Derecho, la aparición de la Filosofía Ju-

\footnotetext{
2 Para mayor información sobre el desarrollo histórico de la Filosofía Jurídica véase, por ejemplo, Kaufmann, Arthur y Hassemer, Winfried. El Pensamiento Jurídico Contemporáneo. Traducción al español de varios autores bajo la dirección de RoBLeS Morchón, Gregorio. Madrid: Editorial Debate, 1992, pp. 47-141; FernÁndez-Galiano, Antonio. Introducción Filosófica al Derecho. $2^{2}$ Edición. Madrid: Editorial Ceura, 1977, pp. 56-58; Segura Ortega, Manuel. Lecciones de Teoría del Derecho. Editorial Universitaria Ramón Areces, 2008, pp. 52-53; De Lucas MarTín, Javier; et al. Introducción a la Teoría del Derecho. $3^{\mathrm{a}}$ Edición. Madrid: Editorial Tirant lo Blanch, 1997, p. 421; VIEHWEG, Theodor. Tópica y Filosofía del Derecho. SEÑA, Jorge M. (Trad.). Madrid: Editorial Gedisa (1964), 1991, pp. 131-133; y BAscuñán VALDÉs, Aníbal. Introducción al estudio de las Ciencias

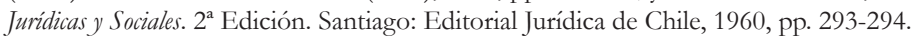


rídica fue muy posterior. En este sentido, no fue hasta la era moderna en que estos contenidos adquirieron una consistencia como saber filosófico de lo jurídico, independiente de la teología y la propia filosofía considerada en sentido general.

La aparición de la Filosofía Jurídica como saber autónomo habría acaecido durante el siglo XVII, en el marco de la Escuela del Derecho Natural Racional. En sentido mediato se atribuye su creación al holandés Hugo Grocio (15831645), quien realizó los primeros intentos sistemáticos en orden a desarrollar un estudio filosófico sobre el fenómeno jurídico independiente de influencias teológicas ${ }^{3}$. Esfuerzos posteriores encontramos en Baruch Spinoza (16321677), Samuel Pufendorf (1632-1694), Christian Thomasius (1655-1728) e Immanuel Kant (1724-1804).

Otro paso importante en la constitución de una Filosofía del Derecho considerada como saber independiente se produce en los inicios del siglo XIX, y se debe a la obra de Friedrich Hegel (1770-1831), titulada Filosofía del Derecho y publicada el año 1820. Con este autor la expresión en cuestión comienza a emplearse en los círculos académicos de Europa.

Hasta el siglo XIX la evolución histórica de la Filosofía Jurídica se identifica mayoritariamente con la historia del Derecho Natural. No obstante, a mediados del siglo XIX, y bajo la aparición del positivismo lógico, la Filosofía Jurídica experimenta un declive notorio. Aparecen diversas escuelas jurídicas destinadas a eliminarla de los estudios jurídicos.

Estas corrientes pretendían sustituir la Filosofía Jurídica por una Teoría General del Derecho, que se ocupara de abstraer y sintetizar, los elementos y conceptos comunes a todos los sistemas jurídicos, prescindiendo de consideraciones filosóficas, ya que estas no tenían un respaldo empírico. En este orden de ideas encontramos la llamada Enciclopedia Jurídica, que fue originada en Italia, la Jurisprudencia Analítica aparecida en Inglaterra y la Doctrina General del Derecho esbozada en Alemania.

A mediados del siglo XX, y al decaer el pensamiento positivista, se produce en Alemania un renacimiento de los estudios filosófico-jurídicos. En esta nueva línea de pensamiento sobresalen Rudolf Stammler (1856-1938), y en general, los representantes de la Escuela Escolástica contemporánea, como por ejemplo, Victor Cathrein (1845-1931), Luis Legaz y Lacambra, y Giorgio del Vecchio (1878-1970).

En la actualidad destacan diversos estudiosos como John Rawls (n. 1927) y su

3 Es la opinión vertida en TORRÉ, Abelardo. Introducción al Derecho. 12 $2^{\mathrm{a}}$ Edición. Buenos Aires: Editorial Abeledo-Perrot, 1999, p. 74; Aftalión, et al. (1988), p. 209; y Enciclopedia Universal Ilustrada Europeo-Americana. Tomo XVIII, Nº18 DEM-DIR (primera parte), N 18 DIS-ECZ (segunda parte) y No28 INT-KZ. Madrid-Barcelona: Editorial Espasa Calpe, 1924, p. 213. 
teoría de la justicia, en un sentido neocontractualista liberal Jürgen Habermas con la teoría del discurso.

Mencionados estos antecedentes históricos, cabe preguntarse ahora qué entendemos por Filosofía del Derecho. Sobre el particular, cabe indicar, primeramente, que el término Filosofía Jurídica es un vocablo complejo integrado por los términos filosofía y derecho. La raíz etimológica de la expresión Filosofía del Derecho se encuentra evidentemente en el término Filosofía, expresión compuesta a su vez de dos vocablos de origen griego: jilo (philo) y sojia (sophia). El primero de ellos (philo) procede del verbo jilein (philein) significando amar, mientras que el segundo (sophia) indica sabiduría, en tanto conocimiento teórico y práctico, propio del sojoV (sophos), es decir, del sabio ${ }^{4}$.

Por tanto, de un punto de vista etimológico, el concepto de filosofía jurídica equivale al amor por la sabiduría referida al Derecho, es decir, al fenómeno jurídico. No se trataría de un saber sobre el Derecho, sino de un anhelo por saber qué es el Derecho, en cuanto intento por abordar el conocimiento integral del mismo.

Ahora bien, en función de su mayor o menor extensión, el concepto de Filosofía Jurídica puede ser entendido bajo tres enfoques distintos:

A. En sentido amplísimo, se entiende todo el pensamiento jurídico. Comprende la Filosofía Jurídica propiamente tal o conocimiento filosófico sobre el Derecho; la Teoría del Derecho, en cuanto conocimiento teórico y abstracto sobre las estructuras formales del ordenamiento jurídico; y la doctrina del Derecho Natural, entendida como el conjunto de teorías iusnaturalistas que hasta el siglo XIX dominaron la historia del pensamiento jurídico.

B. En sentido amplio o genérico, pero algo más restringido, corresponde o engloba tanto a la Filosofía Jurídica propiamente tal, como a la Teoría del Derecho, excluyendo la denominada teoría del Derecho Natural, que en sí constituye un capítulo de la historia de la Filosofía del Derecho, pero no una disciplina cognoscitiva.

C. En sentido restringido, estricto o riguroso, equivale exclusivamente a la Filosofía del Derecho, despojada de los estudios de la Teoría del Derecho. Tal es el concepto que consideraremos como Filosofía del Derecho en este trabajo.

La mayoría de los intentos por conceptuar a la Filosofía Jurídica se han cen-

\footnotetext{
4 Para más detalles sobre la raíz etimológica del término filosofía, véase Coromillas, J. y Pascual, J.A. Diccionario Crítico Etimológico Castellano e Hispánico. Volumen CE-F. $1^{\text {a }}$ Edición 1980. Madrid: Editorial Gredos, $2^{a}$ reimpresión 1987, pp. 898899; Ferrater Mora, José. Diccionario de la Filosofía del Derecho. Volumen A-D y E-J. $1^{\text {a }}$ Edición. Barcelona: Editorial Ariel, 1994, p. 1270; y Abganano, Nicola. Diccionario de Filosofía. $2^{a}$ Edición en español 1963. México: Editorial Fondo de Cultura Económica, $10^{2}$ reimpresión 1993, p. 537.
} 
trado en brindar una definición sobre ella entendida en sentido amplio, o bien, riguroso. Citemos algunos casos.

La profesora española Encarnación Fernández entiende que la Filosofía del Derecho "es una reflexión de carácter filosófico sobre la realidad jurídica". Según expresa el jurista italiano Giorgio del Vecchio, la Filosofía Jurídica "es aquella rama de la Filosofía que concierne al Derecho", es decir, al estudio del Derecho considerado en sus ingredientes o aspectos universales. La conceptúa expresamente como "la disciplina que define el Derecho en su universalidad lógica, investiga los orígenes y los caracteres generales de su desarrollo histórico, y lo valora según el ideal de la justicia trazado por la pura razón"'. El profesor alemán Rudolf Stammler entiende por Filosofía del Derecho "la doctrina de lo que en las reflexiones jurídicas aparece como un valor incondicionado y universal"'.

El jurista germano Arthur Kaufmann, no entrega una definición precisa sobre la Filosofía del Derecho, pero a partir de sus explicaciones esta puede conceptuarse como una "rama de la filosofia que intenta reflexionar y discutir a la manera filosófica en torno a los fundamentos últimos del Derecho, a los problemas jurídicos fundamentales" . Para el profesor Nicolás López Calera, "La Filosofía del Derecho se entiende como un saber metacientifico sobre el derecho, que metodológicamente se apoya en la ciencia jurídica y en las ciencias sociales en general para, a través de la crítica argumentada y razonable, comprender profundamente la compleja realidad del derecho más allá de su mera comprensión cientifica" . A su turno, el profesor Ahrens también ha señalado que la Filosofía Jurídica (o el Derecho Natural según su punto de vista) "es la Ciencia que expone los primeros principios del Derecho concebidos por la razón y fundados sobre la naturaleza del hombre, considerada en sí misma $y$ en sus relaciones con el orden universal de las cosas"10.

También, el jurista Lino Rodríguez-Arias expresa que la Iusfilosofía "es la ciencia suprema que se remonta al ámbito universal, mediante un doble proceso cognoscitivo intuitivo y racional, que lleva a comprender el mundo de los valores jurídicos y las exigencias de la realidad social, tratando de ajustarse esta última a los cánones del derecho natural, para que de este modo predomine el bien común en todas las actividades de la sociedad humana", agrega que, "es la ciencia de la justicia del derecho, tendente a lograr el perfeccionamien-

\footnotetext{
FERnÁNDEZ, Encarnación. Introducción a la Teoría del Derecho, p. 420.

Vecchio, Giorgio del. Filosofía del Derecho. $9^{a}$ Edición revisada por Luiz Legaz y Lacambra, corregida y aumentada. Barcelona: Bosch Casa Editorial, 2a reimpresión 1991, pp. 275 y 279. 
to de las instituciones jurídicas y, por su mediación, el de la persona humana y la comunidad universal" y señala también que "es la conciencia crítica del derecho, que nos ofrece una concepción global y metodológica del mismo, desde las perspectivas epistemológica, gnoseológica y axiológica"11.

En opinión de Rolando Tamayo y Salmorán, “por 'filosofía del derecho’o más correctamente: 'filosofía jurídica', normalmente se entiende una reflexión sobre los principios del derecho y los problemas fundamentales de la teoría jurídica. Dentro de este orden de ideas puede ser descrita como rama de la filosofía general, interesada en el examen de los problemas jurídicos más fundamentales, distinta de las disciplinas que describen el derecho histórico, nacional o internacional" 12 .

Por último, como aproximación al concepto de Filosofía Jurídica nos parece que se trata de una reflexión filosófica acerca del fenómeno jurídico, que pregunta por los fundamentos prístinos del Derecho, esto es, del fenómeno normativo en cuanto es primordial como suceso temporal y en cuanto es primordial su importancia. Al ser una reflexión filosófica comparte todas las características del saber filosófico: una perspectiva crítica, abarcante y ausente de todo fin práctico. Lo prístino puede significar dos cosas: por una parte, implica lo primero en cuanto a sucesión temporal, con ello preguntamos cuándo y cómo aconteció por primera vez el Derecho; y por la otra significa lo primero en cuanto a fundamento, es decir a las bases que dan sustento y asiento al Derecho, con lo cual preguntamos qué es el Derecho, lo que conduce a plantearnos las tres interrogantes clásicas sobre el ser, conocer y deber ser del fenómeno jurídico.

La opinión mayoritaria entre filósofos, iusfilósofos y juristas teóricos, concuerdan en sostener la tesis de que la Filosofía del Derecho, antes que disciplina jurídica, constituye un saber filosófico ${ }^{13}$.

Esta aseveración se funda en que las posibilidades cognoscitivas de la Filosofía Jurídica están dadas por el objeto, métodos y actitud cognitiva de la Filosofía general. Como expresa el profesor Jorge Millas, sus rasgos comunes, como

\footnotetext{
11 Rodríguez,-Arias, Lino. Filosofía y Filosofía del Derecho. Bogotá: Editorial Temis Librería, 1985, pp. $129-130$.

12 Tamayo y Salmorán, Rolando. El Derecho y la Ciencia del Derecho. Universidad Nacional Autónoma de México, México, 1984, p. 139

13 En el mismo sentido el profesor López DE OÑATE señala expresamente que "La filosofía del derecho es de naturaleza genuina e íntimamente filosófica”. López de Oñate, Flavio. Filosofía del Derecho. Bianchi, Alberto S. (Trad.). Buenos Aires: Ediciones Jurídicas Europa-América, 1961, p. 18, reiterando la idea en pp. 27, 30 y 38. En apoyo de dicha posición puede consultarse también Vecchio (1991), p. 275; García Máynez, Eduardo. Introducción al Estudio del Derecho. $37^{\mathrm{a}}$ Edición. México: Editorial Porrúa, 1985, p. 153; Kaufmann y Hassemer (1992), p. 27; Rodríguez-Arias (1985), pp. 124-125; TAmayo y Salmorán (1984), p. 139; Fernández-Galiano (1977), pp. 49 y 60; Fernández, Encarnación, Introducción a la Teoría del Derecho, p. 420; Villoro Toranzo, Miguel. Teoría General del Derecho. México: Editorial Porrúa, 1989, p. 7; TorRé (1999), p. 66; STERnberg, Theodor. Introducción a la Ciencia del Derecho. $2^{a}$ Edición. Editorial Labor, p. 186; y SQueLLA, Agustín. Filosofía del Derecho. Santiago: Editorial Jurídica de Chile, 2001, p. 143.
} 
esencia, fines, formas, limitaciones y métodos son los mismos ${ }^{14}$.

También existen posiciones divergentes que consideran a la Filosofía del Derecho como un saber comprensivo de la Ciencia Jurídica, siendo en todo caso minoritarias. Es la opinión de estudiosos como Felipe González Vicén, Manuel Nuñez Encabo e Ignacio Ara Pinilla ${ }^{15}$.

Para la Filosofía de la Ciencia el objeto material es el fenómeno o contenido del cual se ocupa un determinado saber y/o disciplina cognoscitiva (bien sea filosófica, científica o técnica). Este criterio permite singularizar aquellas disciplinas que tratan de temas divergentes. La Biología, por ejemplo, tiene como objeto material el fenómeno de la vida, diverso al contenido de la Ciencia Histórica, que es el acontecer humano.

Así también la Ciencia del Derecho, disciplina en la cual nos centraremos en los siguientes puntos de este ensayo, posee un objeto material determinado, como es el fenómeno jurídico, es decir, el Derecho.

Mientras tanto, el objeto formal u objeto de investigación, sería la perspectiva o enfoque específico desde el cual se investiga el contenido o materia de una disciplina, es decir, el objeto material. Tal criterio permite reconocer e individualizar aquellas disciplinas que, teniendo un objeto material similar, lo contemplan desde dimensiones distintas. Así por ejemplo, las variadas disciplinas que integran la Ciencia Jurídica tienen como objeto material común el fenómeno del Derecho, pero se distinguen entre sí porque lo captan desde perspectivas distintas ${ }^{16}$. Así sucede con la Historia del Derecho, que se interesa en el aspecto histórico, mientras que la Sociología Jurídica se concentra en factores sociológicos del Derecho.

Ahora bien, hecha la precisión anterior podemos afirmar -en términos generales- que el contenido o materia de la Filosofía Jurídica es el fenómeno del Dere$c h o^{17}$. Tal fenómeno jurídico no puede ser desmembrado en diversos enfoques, ya que es concebido como un todo universal ${ }^{18}$.

\footnotetext{
$14 \mathrm{Al}$ referirse a la Filosofía Jurídica el profesor MiLLAs nos dice “...que sus posibilidades cognoscitivas están dadas en las posibilidades del saber filosófico: esencia, fines formas, limitaciones métodos, son los mismos”. MiLLAs, Jorge. Filosofía del Derecho. Apuntes en mimeógrafo de su curso profesado en la Escuela de Derecho de la Universidad de Chile, Santiago, p. 3. 15 Véase respectivamente GonzÁlez Vicén, Felipe. "La filosofía del derecho como concepto histórico". En Anuario de Filosofía del Derecho, p. 15 y ss., citado en Ara PinilLA, Ignacio. Teoría del Derecho. Madrid: Taller de Ediciones, J.B., 1996, p. 524; Idem, pp. 523-524; y NuñEz EnCABo, Manuel. Introducción al Estudio del Derecho. Madrid: Editorial Alambra, 1979, pp. 165-166.

16 Sobre la distinción entre objeto material y formal en la teoría del conocimiento véase KAUfMANN y HasSEMER (1992), p. 29; Fernández-Galiano (1997), pp. 52-53; Larenz, Karl. Metodología de la Ciencia del Derecho. $2^{a}$ Edición. Barcelona- CaracasMéxico: Editorial Ariel, 2001, pp. 177 y ss.; Calsamiglia (1988), pp. 13, 79 y 131; Williams, Jaime. Filosofía del Derecho. Parte II. Apuntes en mimeógrafo de su curso profesado en la Escuela de Derecho de la Universidad de Chile. Santiago, pp. 67 y 77; y Hübner Gallo, Jorge. Manual de Filosofía del Derecho. $2^{a}$ Edición. Santiago: Editorial Jurídica de Chile, 1963, pp. 18-19. 17 Véase López de Oñate (1961), p. 28; y SQuelda (2001), p. 143.

18 El profesor RodríguEZ-Arias lo menciona expresamente señalando que “.... el objeto material, lo constituye la total realidad de lo jurídico”. Rodríguez-Arias (2001), p. 106.
} 
La Filosofía del Derecho es un saber jurídico de comprensión y máxima integración racional de los datos aportados por la experiencia normativa. No se conforma con aprender las conexiones instrumentales entre las cosas, sino que se extiende a todo aquello que permita comprender el fenómeno jurídico en función de la totalidad de la experiencia.

En consecuencia, la Filosofía Jurídica posee un carácter totalizador o integrador, ya que su objeto formal o perspectiva de estudio es general. Este rasgo ha llevado a algunos autores a sostener que esta disciplina carece de un objeto material específico, ya que se caracteriza por la totalidad de su objeto formal.

Debido a su tendencia a la generalidad, la Iusfilosofía posee un enfoque u objeto de estudio general y totalizador, puesto que interesa el Derecho considerado en todas sus dimensiones ${ }^{19}$. Dicho carácter ha conducido a algunos estudiosos a afirmar que en el fondo la Filosofía del Derecho carece de un objeto material específico, parcelado o determinado, y solo detenta un objeto formal o perspectiva de estudio de índole general y total. Se caracteriza por la totalidad de su objeto formal ${ }^{20}$.

Al respecto, cabe preguntarse si existe una metodología a emplear en la actividad filosófica vinculada al fenómeno jurídico. Al respecto, podemos señalar que lo que caracteriza a toda disciplina es precisamente la existencia de un objeto y método propio. Sin embargo, aunque la Filosofía del Derecho cuenta al menos con un objeto formal característico, resulta extremadamente complejo aseverar la existencia de un método propiamente "filosófico", lo que pone en duda también si la Filosofía Jurídica es efectivamente una "disciplina".

Consideramos que más bien existe una disposición filosófica para el estudio del fenómeno jurídico, que adopta una actitud crítica, recursiva, totalizadora y ausente de fines prácticos. Por ello, antes que concebirla como "disciplina" cognitiva, nos inclinamos por considerar a la Filosofía Jurídica como un "saber" filosófico.

Así, como sostienen numerosos estudiosos, entre los que destaca Theodor Viehweg, la actitud filosófica es el esfuerzo de ejercitar el pensamiento en los

\footnotetext{
19 "Como claramente resulta del nombre, la Filosofía del Derecho es el estudio de lo universal; luego en cuanto la Filosofía tiene por objeto el Derecho, lo toma en sus aspectos universales" (...) "el estudio del Derecho en sus ingredientes universales constituye el objeto de la Filosofía jurídica". Veсchio (1991), p. 275 y 276, respectivamente. Apoyando esta tesis Manuel Atienza escribe que la ".... Filosofía del Derecho no tiene tampoco un terreno acotado en exclusividad en el conjunto de los saberes jurídicos y sociales, sino que su campo es más bien el de las relaciones entre estos diversos sectores de la cultura; su lugar está, precisamente, en las fricciones y en los vacíos que se producen en el funcionamiento de los mismos. Por eso la filosofía del Derecho puede tener la pretensión de ser un saber totalizador, en la medida en que su punto de partida y llegada sean esos otros saberes y prácticas, es decir, en la medida en que no se resuelva en especulación cerrada en sí misma...”. Atienza (1985), pp. 371-372. En idéntico sentido véase también Villoro Toranzo (1989), pp. 7-8; Viehweg (1991), p. 25; Rodríguez-Arias (1985), p. 106; Fernández-Galiano (1977), p. 60; y López de Oñate (1961), p. 37; y Millas, Jorge. Filosofía del Derecho. Santiago: Ediciones Publilex, 1970, p. 40.

20 Es la opinión, por ejemplo, de Kaufmann y Hassemer (1992), p. 29.
} 
límites mismos de su posibilidad, es decir, de cuestionar radicalmente ${ }^{21}$ las cosas. Por ello, el profesor Arthur Kaufmann nos explica que la Filosofía Jurídica tiende siempre a adoptar una posición trascendente al sistema jurídico ${ }^{22}$.

En definitiva, la Iusfilosofía es radical, puesto que no puede aceptar nada como incuestionable, lo que deriva de su carácter analítico, recursivo, crítico y especulativo $^{23}$.

Por último, debemos destacar que la Filosofía Jurídica no se concentra en obtener resultados prácticos, ya que obedece a un interés desinteresado por la sabiduría, que caracteriza también a la Filosofía en sentido general ${ }^{24}$. El proceso de intelección no se limita a la acción, sino que exige comprender los fundamentos del Derecho, ensanchando infinitamente el campo del conocimiento jurídico. Por ello, la carencia de practicidad conlleva a la generalidad.

\section{Relaciones entre Ciencia Jurídica y Filosofía del Dere- $\mathrm{CHO}$}

Recordemos que tanto la Ciencia del Derecho como la Filosofía Jurídica, tienen un idéntico objeto material, que es el Derecho. Este elemento común permite calificarlas a ambas como saberes jurídicos.

Uno y otro conocimiento, sin embargo, presentan diferencias diametrales, las cuales pueden estructurarse sobre la base de cinco parámetros, que en todo caso no constituyen una enumeración taxativa. Dichos criterios son a nuestro juicio los siguientes: la actitud reflexiva, la amplitud del objeto formal o enfoque de estudio, la relación entre el objeto material o contenido de la investigación y su perspectiva u objeto formal, las dificultades en torno al objeto formal, y finalmente, lo concerniente al problema de investigación.

\section{A. LA ACTITUd Reflexiva}

La primera diferencia entre Filosofía y Ciencia Jurídica que cabe destacar, es aquella referente a la actitud reflexiva.

En tal sentido, el profesor Arthur Kaufmann enfoca la distinción a partir de la

21 Para el profesor Viehweg la Filosofía del Derecho: "Desea en su campo de problemas, cuestionar radicalmente, es decir, filosóficamente". VIEHWEG (1991), p. 25

22 Véase Kaufmann y Hassemer (1992), p. 28.

23 En este sentido puede consultarse Kaufmann y Hassemer (1992), p. 28; FernándeZ-Galiano (1977), p. 60; López de OÑate (1961), p. 47; Atienza (1985), p. 372; y también de forma indirecta en Viehweg (1991), p. 25.

24 Afirmando categóricamente esta posición, el profesor chileno Jorge HüBner señala que “...la filosofía del derecho no sirve para fin práctico alguno... éste el verdadero título de nobleza de la filosofía del derecho; el de estar exenta de esta inmediata degradación, que es la practicidad...”. HüBNER (1963), p. 48. 
denominada Dogmática o Sistemática Jurídica, disciplina que razona a partir de afirmaciones dogmáticas o ex datis, esto es, de premisas o antecedentes considerados como auténticos sin ser cuestionados previamente ${ }^{25}$. Estos "dogmas" corresponden al ordenamiento jurídico y son aceptados acríticamente en virtud de la regla de adhesión al Derecho positivo. De esta forma, el jurista en sentido estricto mantiene una actitud dogmática e inmanente al sistema jurídico, según la cual, toda argumentación empleada al someter a examen una norma jurídica, deja siempre intangible el orden jurídico imperante ${ }^{26}$.

Por el contrario, la Filosofía y enseguida la Filosofía del Derecho, mantienen una actitud filosófica, por ello recursiva, especulativa y trascendente al sistema normativo. A diferencia del tratadista dogmático, el filósofo jurídico es radical, para él no existe un ex datis, puesto que no puede aceptar nada como incuestionable; se dirige más a los fundamentos que las ciencias jurídicas particulares ${ }^{27}$.

\section{B. LA AMPLITUD DEL OBJETO FORMAL}

A semejanza de las ciencias particulares, la Ciencia Jurídica posee un objeto formal reducido, concreto, precisado o acotado, en tanto se dirige a un fenómeno jurídico en particular, y nunca al Derecho considerado en su totalidad ${ }^{28}$. Por este motivo, en la jerga jurídica, resulta más adecuada la expresión "Ciencias del Derecho" 29 .

Por otra parte, tal como acontece con la Filosofía en sentido genérico, la Filosofía Jurídica se caracteriza por la totalidad de su objeto formal, es decir, por una perspectiva u objeto de análisis indefinido, universal e indeterminado. De esta forma, la Filosofía del Derecho no se ocupa de lo individual, ni de un conjunto de elementos individuales, sino de la estructura fundamentante, esto es, del Derecho considerado como un todo. Precisamente este carácter holístico

\footnotetext{
25 Sobre el concepto de dogma véase, por ejemplo, Real Academia Española (1992), Diccionario de la Lengua Española, p. 771; Ferrater Mora (1994), Diccionario de la Filosofía del Derecho, pp. 929-930; y Brugger (1993), Diccionario de Derecho, p. 188. 26 “... la filosofía del derecho no es identificable con la ciencia jurídica, y sobre todo no se la debe identificar de modo alguno con la dogmática jurídica (...) Todo tratadista de una disciplina dogmática parte de presupuestos que acepta como verdaderos sin previo examen, pensando a partir de los datos que le son dados (ex datis)." Kaufmann y Hassemer (1992), p. 27.

27 "En disonancia con la dogmática, la filosofía como mínimo tiene que intentar resolver las cuestiones radicales o de fundamento último que subyacen a los problemas y a los presupuestos tanto de las ciencias como de los sistemas. Expresado en otras palabras: la filosofía tiene que adoptar una posición trascendente al sistema... Nada hay en la filosofía que no pueda ser problematizado, incluida su propia naturaleza; y lo propio sucede con la filosofía del derecho. El filósofo, por principio, no puede aceptar nada como incuestionable. En este sentido es lícito afirmar que la filosofía procede 'más radicalmente', va más a los fundamentos que las ciencias particulares". KAUfmann y Hassemer (1992), p. 28. Planteando esta diferencia de actitud entre Filosofía y Dogmática Jurídicas, el profesor Torré nos dice que "... el jurista strictu sensu utiliza una serie de nociones (derecho, norma, sujeto, relación jurídica, justicia, etc.), que da por supuestas; en cambio, el filósofo del derecho, encara como problema lo que es un supuesto para el científico del derecho, tratando de llegar a un esclarecimiento cabal de los conceptos". TorRé (1999), p. 66.

28 "Lo característico de las ciencias particulares es, como su propio nombre indica, que se dirigen siempre a lo particular, a lo individual, y nunca a un ente considerado en su totalidad". KAUfmann y Hassemer (1992), p. 29.

29 Sobre el empleo de esta expresión en la literatura académica véase, a modo de ejemplo, SEGURA OrTEGA (2008), p. 66.
} 
genera luego el problema de determinación de su objeto material ${ }^{30}$.

Como señala Theodor Viehweg, la Filosofía del Derecho no desea preguntar dentro de los límites de una investigación especializada, por ejemplo, de la Historia del Derecho, como tampoco de una investigación dogmática ${ }^{31}$.

En síntesis, la Ciencia del Derecho procede tan solo a estudiar el conocimiento jurídico de carácter científico, mientras que la Filosofía Jurídica, por su carácter totalizador, se dirige también al tema ontológico y axiológico vinculado al fenómeno jurídico ${ }^{32}$. Incluso la perspectiva gnoseológica de la Ciencia Jurídica es más estrecha por cuanto se centra exclusivamente en problemas epistemológicos, que desde diversas disciplinas estudian el tema científico, en tanto que la Filosofía del Derecho se ocupa de cuestiones gnoseológicas y epistemológicas, dirigidas tanto al conocimiento científico jurídico, como al saber jurídico en general.

\section{RELACIÓN ENTRE OBJETO MATERIAL Y FORMAL}

Consecuencia de la anterior diferencia, surge una tercera que ya ha sido esbozada indirectamente. Como señala el doctor Kaufmann, en la Ciencia del Derecho existe claramente una doble vinculación entre objeto material y objeto formal de estudio. El objeto material o contenido de estudio en las ciencias particulares, y por tanto, también en la Ciencia Jurídica, es un objeto propio, concreto, específico, parcelado y determinado, por cuanto su investigación se efectúa bajo una perspectiva también determinada que es el objeto formal ${ }^{33}$.

Sin embargo, en el caso de la Filosofía Jurídica no se presenta esta doble vinculación. La Filosofía y la Filosofía Jurídica carecen de un objeto material determinado, solo poseen un objeto formal de carácter indefinido, universal,

\footnotetext{
30 “... la filosofía se caracteriza por la totalidad de su objeto formal. La tarea de la filosofía no es tratar de lo individual, ni tampoco de la pluralidad de elementos individuales, sino del todo, de la estructura, de lo fundamentante. En esto radica uno de los más arduos problemas del pensamiento filosófico". KAufmann y Hassemer (1992), p. 29. "La filosofía del Derecho -como toda filosofía- (...) quiere entender la universalidad de los seres y el lugar que ocupa el Derecho entre ellos. La TGD es mucho menos ambiciosa y se acerca a las causas próximas; ciertamente se quiere en contacto directo con el Derecho positivo pero se distancia un tanto de él para contemplar el orden racional latente en la globalidad de los Derechos positivos". Villoro Toranzo (1989), p. 7. Para mayor amplitud del tema véase también Fernández-Galiano (1977), pp. 53-54.

31 Para el profesor Vienweg, la Filosofía del Derecho: "No desea preguntar dentro de los límites (para otros fines razonables) de una investigación especializada, por ejemplo, de la historia del derecho francés medieval, y tampoco dentro de los límites (igualmente razonables para otros fines) de una investigación dogmática”. VIEHWEG (1991), p. 25.

32 Sobre el afán axiológico de la Iusfilosofía el profesor ViLLORO Toranzo expresa que “... la Filosofía del Derecho con frecuencia se detiene a reflexionar como debe ser el Derecho y no queda satisfecha con la mera descripción sobre el Derecho histórico". Villoro Toranzo (1989), p. 8. En este último sentido Radbruch señala que el versar sobre "el Derecho positivo: esto es lo que diferencia a la ciencia jurídica en sentido estricto de la Filosofía del Derecho y de la política jurídica, que tratan, respectivamente, del valor del Derecho y de los medios que sirven para la realización de este valor". RADBRUCH, Gustav. Introducción a la Filosofía del Derecho. Roces, Wenceslao (Trad.). $1^{\mathrm{a}}$ Edición en español. Buenos Aires: Editorial Fondo de Cultura Económica, $5^{\text {a }}$ reimpresión 1993, p. 9.

33 "A las ciencias particulares les caracteriza su vinculación a un determinado objeto material, a un ente concreto, cuya investigación se efectúa bajo un aspecto determinado, que es el objeto formal”. KAUfMANn y Hassemer (1992), p. 29.
} 
indeterminado y abarcante, en tanto se ocupan, respectivamente, del "ser" y del "ser Derecho", desde una perspectiva siempre integral ${ }^{34}$.

\section{Dificultad del objeto formal}

La Ciencia del Derecho no tiene un objeto formal dificultoso, ya que al igual que en las ciencias particulares, el número de problemas es por principio limitado, en tanto su objeto formal de estudio es acotado. Es así, que para Kaufmann toda ciencia particular puede agotar, teóricamente al menos, su perspectiva y materia de estudio ${ }^{35}$.

Mientras tanto, la Filosofía del Derecho tiene un objeto formal problemático. En efecto, la carencia de un objeto material delimitado y la universalidad de su objeto formal, generan también un objeto formal dificultoso, puesto que este último se encuentra en constante expansión y el objeto material tiende a ir más allá de las fronteras empíricas ${ }^{36}$.

\section{E. Planteamiento del problema}

En la Ciencia Jurídica la dirección de la interrogante o problema viene determinada por su objeto formal, puesto que este se dirige a lo particular. En otras palabras, el problema que se plantea el jurista teórico - bien sea dogmático, comparatista, iushistoriador u otro - surge del propio objeto formal de su disciplina ${ }^{37}$.

En el caso de la Filosofía Jurídica, sin embargo, el planteamiento del problema no puede esbozarse a partir de su objeto formal, debido a su carácter universal. Esto porque nuestro pensamiento no puede abarcar la totalidad del fenómeno jurídico, sino en referencia a lo particular, es decir, a un sector del Derecho, debiendo iniciarse el estudio y planteamiento del problema por una interrogante concreta $^{38}$.

\footnotetext{
34 "En la filosofía no se nos presenta de esta manera la doble vinculación al objeto material y al objeto formal... carece de un objeto material determinado y... el objeto formal que a ella subyace es indefinido: el 'ser en su último fundamento' ". Kaufmann y Hassemer (1992), p. 29.

35 "En las ciencias particulares, precisamente porque se trata de investigar lo individual, es posible que el investigador aislado, trabajando en su gabinete de estudio o en su laboratorio, pueda conseguir por sí solo un descubrimiento científico". Kaufmann y Hassemer (1992), p. 29.

36 "Son estas dos características, la carencia de objeto material y la universalidad del objeto formal, las que hacen tan problemáticos tanto al conocimiento como al método filosófico. Aunque para la filosofía sea válido el adoptar como punto de partida la realidad individual derivada de la experiencia (por ejemplo, una concreta norma jurídica), nunca podrá constituir su propio objeto sino en este caso el medio para alcanzar lo que se encuentra más allá, lo 'trascendente' (en el ejemplo citado, planteándose la pregunta de qué es en último término la norma jurídica)”.KAUfMANn y Hassemer (1992), pp. 29-30. 37 "En la ciencia particular (dogmática) la dirección de la pregunta viene determinada por su objeto; puesto que de antemano va dirigida a lo individual, el planteamiento de la cuestión puede vincularse inmediatamente a dicho objeto. Hablando en términos más concretos: el problema que se le plantea al jurista resulta sin más de su correspondiente objeto formal...”.KAUfmann y HaSSEMER (1992), p. 31.

38 'En la filosofía, y, por tanto, también en la filosofía del derecho, las cosas son muy distintas, ya que su 'objeto' es la to-
} 


\section{La Ciencia Jurídica}

Hablar de la Ciencia del Derecho implica hacer mención de la Jurisprudencia; sin embargo, hablar de Jurisprudencia no importa referirse exclusivamente a la Ciencia Jurídica. Ello se debe a que al igual que el concepto de Derecho, la Jurisprudencia es un término vago y ambiguo, pues admite variados significados que en términos generales pueden sintetizarse en tres.

De una parte, la Jurisprudencia se identifica con la denominada Ciencia del Derecho. De otra -probablemente más generalizada hoy día en el ámbito de los sistemas jurídicos continentales-, el término se homologa al proceso de interpretación y aplicación del Derecho hecha por los tribunales, y de una tercera, emparentada con la anterior, significa el conjunto de decisiones jurisdiccionales sobre una materia jurídica determinada ${ }^{39}$.

Es exclusivamente el primero de estos alcances, en el sentido de ciencia, estudio o conocimiento del Derecho, que por lo demás es el originario en términos etimológicos e históricos, aquel al cual nos abocaremos. Dicho concepto admite a su vez diversas acepciones que divergen precisamente en cuanto a la extensión del saber que esta Jurisprudencia comprende.

La expresión jurisprudencia procede de la voz latina Jurisprudentia o Iurisprudentia, cultismo que se compone de dos vocablos, los cuales son: ius o iuris, que significa "derecho"; y prudentia, esto es, "sabiduría o conocimiento", derivado a su vez del término prudens, que significa "sabio o conocedor". Prudens proviene de providens, participio presente del verbo provideo, es decir, "prever", viniendo a expresar originariamente "el que prevé o el previsor", por ende "el que está al tanto, el que ve previamente incluso antes de que la cosa misma se manifieste a la vista", en definitiva "el que sabe, el sabio".

De este modo, el significado etimológico del término Jurisprudencia o Ciencia Jurídica viene a ser el de "sabiduría o conocimiento referente al Derecho", consistiendo a fin de cuentas, en el "estudio o saber sobre el Derecho"40.

La expresión Ciencia Jurídica, empleada en el sentido de sabiduría o conocimiento sobre el Derecho, puede ser utilizada con tres alcances diversos ${ }^{41}$.

talidad del ser; en el caso de la filosofía jurídica, la totalidad del derecho. Pero, como hemos señalado, nuestro pensamiento no puede abarcar la totalidad del ser o del derecho de manera inmediata y de un solo golpe (uno actu), sino en referencia a lo singular, comenzando por una parte del todo; y, consiguientemente, la filosofía no puede concretar su planteamiento metódico partiendo de su objeto". Kaufmann y Hassemer (1992), p. 31.

39 Sobre las diversas acepciones del término Jurisprudencia véase Couture (1993), Vocabulario Jurídico, p. 372; REAL Academia Española (1992), Diccionario de la Lengua Española, p. 1215; Capitant (1986), Vocabulario Jurídico, p. 338; Escriche (1995), Diccionario Razonado de Legislación y Jurisprudencia, p. 1131; y GARCía Garrido, Manuel Jesús. Diccionario de Jurisprudencia Romana. $3^{a}$ Edición. Madrid: Editorial Dykinson S.L., 2a reimpresión 1993, p. 191.

40 Para mayor información véase Couture (1993), p. 372.

41 Sobre el empleo de esta distinción véase Torré (1999), p. 52; y Bascuñán VaLdés (1960), p. 291. 
A. En sentido amplísimo, comprende todo saber cuyo objeto de conocimiento sea el fenómeno del Derecho, lo cual incluye también a la Filosofía del Dere$\mathrm{cho}^{42}$.

B. En sentido amplio, pero más restringido o semirrestringido, engloba todo saber científico abocado al estudio del fenómeno jurídico, lo que se ha denominado Ciencia del Derecho en sentido lato, comprensivo de las diversas ciencias jurídicas particulares, quedando excluida la Filosofía Jurídica ${ }^{43}$.

C. En sentido restrictivo o riguroso, se concibe como aquella rama de la ciencia jurídica que estudia el Derecho positivo en vigencia, denominada habitualmente Dogmática Jurídica.

En nuestro concepto, las Ciencias del Derecho corresponden al grupo de las ciencias sociales, cuyo contenido o materia de investigación en común es el fenómeno jurídico, pero dotada de un objeto formal o perspectiva de estudio especifico, que depende de cada una de las ciencias jurídicas particulares que la componen.

Utilizamos la denominación de ciencias jurídicas en cuanto conjunto de estudios sistemáticos y metódicos sobre el Derecho, que desde diversos ángulos especificos pretenden alcanzar una aproximación ordenada, coherente y minuciosa del fenómeno jurídico.

\section{Divisiones de la Ciencia Jurídica ¿Ciencia del Derecho o Ciencias del Derecho?}

Una precisión de rigor en nuestro análisis es que la Ciencia Jurídica en sentido genérico constituye en el fondo una abstracción, porque en virtud de su acotado objeto de estudio, lo que existe en concreto son diversas ciencias jurídicas particulares.

En efecto, la Jurisprudencia considerada en sentido amplio o general constituye una verdadera abstracción, pues debido a su acotado objeto de investigación suele cultivarse en forma fragmentada, dando cabida a diversas ciencias jurí-

\footnotetext{
42 Con este alcance se define también la Ciencia Jurídica como "el sistema de conocimientos verdaderos y ciertos referentes al Derecho”. Enciclopedia Universal Ilustrada Europeo-Americana (1924), tomo XVIII, Nº18, p. 213.

43 Esta segunda acepción es considerada respectivamente por CouTure (1993), Vocabulario Jurídico, p. 218; y Salmond, W., Jurisprudence, p. 1, citado en Calsamiglia (1988), p. 130. En el mismo sentido Miguel Reale señala que: “... La Ciencia del Derecho estudia el fenómeno jurídico en todas sus manifestaciones y momentos. Esta experiencia interesa a los científicos del Derecho no solamente cuando está perfeccionada y formalizada en leyes, sino también a medida que se va manifestan-

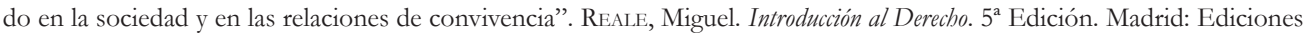
Pirámide, 1982, p. 235. Idéntica posición es adoptada finalmente por el profesor Jorge MuLtas quien la denomina Ciencia Jurídica en sentido lato. Véase Millas, Jorge. Filosofía del Derecho. Santiago: Ediciones Publilex, 1970 , pp. 18 y ss.
} 
dicas particulares ${ }^{44}$, la Dogmática Jurídica, el Derecho Comparado, la Historia del Derecho, la Sociología Jurídica, la Antropología Jurídica, etc.

Recordemos que todas estas disciplinas jurídicas o Ciencias del Derecho, tienen como elemento común el objeto material de estudio, que para el caso es justamente el fenómeno jurídico, siendo el objeto formal, es decir, la perspectiva de estudio de este objeto material compartido, el principal criterio de distinción entre unas y otras ${ }^{45}$.

Lo que sucede es que generalmente se reduce el concepto de ciencia jurídica exclusivamente a la Dogmática Jurídica ${ }^{46}$. En el fondo la Ciencia del Derecho es homologada muchas veces a la Dogmática Jurídica.

Esta visión de género a especie, compartida por el común de los juristas - y no obstante su carácter restringido -, es plenamente comprensible, ya que desde un punto de vista práctico e incluso histórico la Jurisprudencia Dogmática representa la actividad medular de la Ciencia Jurídica. De hecho la mayoría de los estudios jurídicos son de tipo dogmático, es decir, abocados al Derecho positivo vigente en un territorio y tiempo determinado.

En resumen, Ciencia Jurídica y Dogmática del Derecho tienen una estrecha vinculación en un sentido que va de lo genérico a lo específico. La Dogmática Jurídica es entonces la rama o componente fundamental de la Ciencia del Derecho, y por tanto, una forma particular de hacer Ciencia Jurídica ${ }^{47}$, pero no es la única.

Ahora bien, atendido el campo de esta breve investigación, en esta oportunidad nos ocuparemos exclusivamente de la aludida Dogmática Jurídica o Ciencia del Derecho considerada strictu sensu. Pero, ¿qué se entiende por tal? Para intentar una respuesta, debemos precisar que han sido filósofos, teóricos y dogmáticos del Derecho quienes han intentado definir lo que se entiende por Jurisprudencia en sentido estricto ${ }^{48}$. Para el iusfilósofo y penalista Gustav Radbruch, la Dogmática Jurídica "es la ciencia que versa sobre el sentido objetivo

\footnotetext{
44 “... los diversos aspectos de esta Ciencia Jurídica general pueden ser estudiados parcialmente y darán lugar a diversas ciencias jurídicas parciales o ciencias del Derecho". NuÑEZ EnCABO (1979), p. 164.

45 En este sentido véase Kaufmann y Hassemer (1992), p. 29; Larenz (2001), pp. 25 y ss. y 177 y ss.; Calsamiglia (1988), pp. 13, 79 y 131; Williams, pp. 67 y 77; y Pacheco (1993), p. 702. Este último hace radicar la distinción más allá del objeto formal, considerando también el método, puesto que en las Ciencias Jurídicas Puras ambos serían estrictamente jurídicos, mientras que en las Derivadas ellos serían de carácter mixto.

46 Utilícense como sinónimos de esta disciplina, los términos: Dogmática Jurídica, Ciencia del Derecho Positivo, Sistemática Jurídica, Ciencia del Derecho stricto sensu o en sentido estricto, Jurisprudencia Dogmática o Sistemática, Ciencia del Derecho positivo o particular, Ciencia Dogmática o Sistemática del Derecho, Jurisprudencia Científica o Normativa, Ciencia Dogmático-Jurídica o Dogmático-Sistemática, Jurisprudencia Teórica y Jurisprudencia Doctrinaria. En el medio alemán dicha disciplina es conocida como Rechtsdogmatik o Rechtswissenchaft.

47 Sosteniendo esta relación se encuentran, entre otros autores: Díaz (1992), p. 70; RoBles (1988), p. 163; Couture (1993), Vocabulario Jurídico, p. 239; Atienza (1985), p. 292; Nuñez EnCabo (1979), p. 161; y Calsamiglia (1988), p. 13.

48 Supra nota 46.
} 
del Derecho Positivo"49. Por su parte, el profesor W. Salmond ha señalado que "la jurisprudencia es el nombre dado a un cierto tipo de investigación de naturaleza abstracta, general, y teórica que intenta descubrir los principios esenciales del Derecho y del sistema legal" ${ }^{\prime 50}$. Asimismo, en concepto de Luis Recasens Siches, la Sistemática del Derecho es "la disciplina jurídica sobre un orden positivo dado" ${ }^{51}$. Luego, en opinión de Helmut Coing, la Jurisprudencia Dogmática "consiste en la investigación metódica del contenido de un orden jurídico positivo con el objetivo de hacerlo aplicable" 52 . A continuación, según afirma Miguel Villoro Toranzo, la Sistemática Jurídica "es el conocimiento ordenado conforme a sistema del Derecho positivo o de alguna parte del mismo" 53 .

A su turno, don Jaime Williams, profesor chileno, sostiene que la Dogmática Jurídica o Ciencia del Derecho en sentido estricto puede ser entendida como "el conocimiento racional y sistemático del Derecho Positivo" 54 . También, el doctor español Eduardo García Máynez expresa que la Dogmática Jurídica es la ciencia "que tiene por objeto la exposición ordenada y coherente de los preceptos jurídicos que se hallan en vigor en una época y un lugar determinados, y el estudio de los problemas relativos a su interpretación y aplicación"55. Ahora bien, para el jurista argentino Abelardo Torré la Sistemática Jurídica "es la ciencia que tiene por objeto el estudio, o mejor aún, la interpretación, integración y sistematización de un ordenamiento jurídico determinado, para su justa aplicación"s6.

El profesor español Albert Calsamiglia, entiende por Dogmática del Derecho "el saber que trata de describir las normas jurídico-positivas y que tradicionalmente se ha denominado dogmática jurídica o jurisprudencia". Sostiene que "en sentido estricto, jurisprudencia es un saber teórico sobre el Derecho" y agrega que "es aquel conjunto de actividades que llevan a cabo dentro de una comunidad instituida por los juristas"57. Según escribe Miguel Reale, la Jurisprudencia Científica "es la ciencia positiva del Derecho Positivo (...) especificación de la Teoría General del Derecho en el ámbito y en función del ordenamiento jurídico y de su aplicación... estudio sistemático de los preceptos jurídicos" ${ }^{\prime 5}$. En sentido restringido -desde el punto de vista del sistema de fuentes-, el connotado jurista uruguayo Eduardo Couture entiende por Dogmática o Doctrina Jurídica aquella "parte de la ciencia jurídica, constituida

49 RadBruch (1993), p. 9.

50 Salmond, W. Jurisprudence. $12^{a}$ Edición. Londres: Ed. Sweet \& Maxwell, p. 1, citado en Calsamiglia (1988), p. 130.

51 El profesor Recasens Siches es citado en Vecchio (1991), p. 29.

52 Coing, Helmut. Filosofía del Derecho. Barcelona: Editorial Ariel Barcelona, 1970, p. 266.

53 Villoro Toranzo (1989), p. 11.

54 Williams, p. 100.

55 García Máynez (1985), p. 298.

56 Torré (1999), p. 52.

57 Calsamiglia (1988), pp. 12-13 y 130-131.

58 Reale (1982), pp. 235 y 244. 
por la opinión de los jurisconsultos, que conjuntamente con la legislación y la jurisprudencia, integra las fuentes reales del derecho"59.

Finalmente, en nuestra opinión, la Dogmática Jurídica es la Ciencia sobre el Derecho positivo, esto es, sobre el ordenamiento jurídico considerado como presupuesto dogmático de estudio. Se trata de una rama pura u originaria de la Ciencia Jurídica que se aboca al estudio inmanente del Derecho positivo vigente en un determinado Estado, el cual describe, argumenta (elaborando conceptos doctrinales), interpreta (dilucidando su sentido y alcance) y sistematiza (reorganizando, coordinando y clasificando), sin perjuicio de contribuir a su aplicación, reforma y perfeccionamiento. En el fondo, la Sistemática Jurídica es el estudio dogmático o inmanente del Derecho positivo, predominantemente descriptivo pero con una finalidad profundamente pragmática, destinada a la aplicación y perfeccionamiento de su propio objeto formal de estudio: el ordenamiento jurídico en vigencia.

La Sistemática Jurídica dice relación principalmente con los contenidos normativos, por cuanto es una ciencia jurídica cuyo objeto formal de estudio se dirige al Derecho positivo vigente en una comunidad.

En efecto, la Ciencia Sistemática del Derecho se especializa en el estudio de normas jurídicas. Tiene por objeto fundamental la exposición del Derecho positivo normativamente vigente en una comunidad y momento histórico específico, y dentro de su ámbito de validez espacial ${ }^{60}$.

La perspectiva de la Dogmática, es el ordenamiento jurídico en vigencia, al cual se adhieren las investigaciones y comentarios dogmáticos que sobre aquél se elaboran, lo que en definitiva constituye su función descriptiva del Derecho. Así, en la jerga jurídica se la conoce igualmente como Jurisprudencia Normativa o Ciencia del Derecho Positivo.

\section{La Teoría del Derecho}

Los fundamentos de la Teoría del Derecho en el ámbito de la Filosofía de la Ciencia se encuentran primero en el utilitarismo y empirismo inglés del siglo XVIII, luego en el positivismo científico de finales del siglo XIX, y por último, en la Filosofía Analítica y el positivismo lógico de comienzos del siglo XX,

59 Couture (1993), p. 239.

60 “.... al versar sobre un Derecho positivo vigente, la Ciencia del Derecho es una ciencia normativa, es una ciencia de normas o sobre normas". Rodríguez Molinero (1991), p. 147, también en pp. 142-144 y 147-148. En este sentido véase también Larenz (2001), pp. 183 y ss.; TAmayo y Salmorán (1984), pp. 143-144; Calsamiglia (1988), p. 79; Atienza (1985), p. 290; Fernández, pp. 407-408 y 412; Díaz (1992), pp. 60-62; Segura Ortega (2008), p. 25; Nuñez Encabo (1979), pp. 167 y 169; Reale (1982), p. 237; Nino (1991), p. 337; Latorre (1990), pp. 5-6; FernándeZ-Galiano (1977), p. 53; y SQueLLA (2001), p. 193. 
propios del Círculo de Viena, dentro del cual destacan numerosos filósofos de la ciencia como Moritz Schlick (n. 1882), Hoppers, Rudolf Carnap (n. 1891), Alfred Ayer, Albert Einstein, Bertrand Russell (1872-1970), George Edward Moore (1873-1958), Karl Popper (n. 1902), Hempel, Reichenbach y un Ludwig Wittgenstein inicial (n. 1889).

Pero el antecedente directo en el área de la Epistemología Jurídica, lo constituye el desarrollo de las escuelas formalistas y el positivismo jurídico metodológico desarrollado entre finales del siglo XIX y comienzos del XX, cuyos máximos representantes fueron, John Austin, Adolf Merkel, Hans Kelsen, Fritz Schreier, Félix Kaufmann, Herman Heller y Carl Schmitt, entre otros.

Se considera como fundador de la Doctrina General del Derecho al jurista Adolf Merkel, quien fue seguido de Carl Bergbohm, Ernest Rudolf Bierling, Félix Somló, y el mismo Rudolf Stammler. Fue el mencionado administrativista alemán Adolf Merkel, quien, inspirado en los postulados teóricos del Círculo de Viena y el positivismo jurídico metodológico, acuñó la frase, denominando como Allgemeine Rechtslehre o Teoría General del Derecho, a una disciplina jurídica destinada precisamente a estudiar y llevar a un mayor grado de abstracción los problemas teóricos y generales de la Ciencia del Derecho, que excedían la particularidad y practicidad de aquellos que abordara la Dogmática Jurídica.

El propósito de esta ciencia consistía en construir una jurisprudencia general que extrajera los elementos, estructuras y conceptos jurídicos fundamentales comunes a todo ordenamiento jurídico avanzado, a partir del análisis de las diversas ramas del Derecho Positivo de cada Estado.

Esta nueva orientación jurídica, excluía intencionalmente todos aquellos contenidos estimados como "metafísicos", propios de la Filosofía del Derecho, de substrato principalmente axiológico-jurídico, que por ese se motivo se consideraba, debían ser desterrados de la Ciencia del Derecho. Dicha actitud condujo a que Gustav Radbruch señalara, en su segunda etapa intelectual, que la Teoría General habría llegado a ser una verdadera eutanasia de la Filosofía Jurídica ${ }^{61}$.

A la mencionada escuela alemana, habría antecedido la correspondiente Jurisprudencia Analítica Inglesa encabezada por John Austin, que, basada en el pensamiento de Jeremy Bentham, optó por una metodología inductiva, a diferencia de la Doctrina General, que privilegió el análisis deductivo. Con posterioridad a la escuela británica y a la jurisprudencia general alemana vendrán Hans Kelsen y la Escuela Vienesa, introduciendo una versión particular de la Teoría Jurídica que su creador denominará Reine Rechtslehre o Teoría Depurada del Derecho.

61 Véase Radbruch, Gustav. Rechtsphilosophie, p. 175, citado en Kaufmann y Hassemer (1992), p. 93. 
En la actualidad, la disciplina en estudio continúa evolucionando, y los expertos en su mayoría prefieren utilizar el término Teoría del Derecho, o bien, Teoría Fundamental del Derecho, considerando a la Allgemeine Rechtstlehre, como un momento histórico en la evolución de la epistemología y metodología jurídicas desarrolladas a lo largo del siglo $\mathrm{XX}^{62}$.

Los estudiosos y teóricos del Derecho han elaborado diversas aproximaciones al concepto de Teoría del Derecho ${ }^{63}$. Para la profesora Encarnación Fernández la Teoría Fundamental del Derecho "es un sector de la Ciencia del Derecho que, sobre la base de la observación y la explicación de los diversos sistemas normativos, estudia los problemas que son comunes a todos o a la mayor parte de los sistemas de Derecho" "44. A su turno, el jurista Manuel Nuñez Encabo define este saber sobre el Derecho como "aquel tipo de conocimientos cientificos que busca, a través, principalmente, de categorías jurídicas y clasificaciones, una expresión sintética de las estructuras y conceptos comunes a las normas que componen las diferentes ramas jurídicas (partiendo de las propias normas) para facilitar la aplicación y la crítica de las mismas"65. Ahora bien, considerándola como una disciplina jurídica autónoma de la Filosofía y Dogmática Jurídicas, Abelardo Torré la conceptúa como "la ciencia que tiene por objeto la formulación de conceptos jurídicos generales, obtenidos luego de comparar regímenes jurídicos de distintos Estados. A tal fin y como es habitual en este tipo de ciencias, se generaliza sobre la base de los caracteres comunes, previa abstracción de las diferencias"

En opinión del profesor chileno Máximo Pacheco, la Teoría General del Derecho "es una disciplina que tiene por objeto la construcción de los conceptos fundamentales de la Dogmática Jurídica"67.

A su turno, el profesor P. Piovani señala que la Doctrina General del Derecho es "el estudio de la estructura en que se compone y en que se articula un sistema normativo" $"$. Siguiendo al jurista chileno Jaime Williams, quien sin embargo no esboza una definición específica sobre la Teoría Jurídica General, se puede

\footnotetext{
62 Para mayor amplitud sobre el tema véase RodríGuEz-Arias (1985), pp. 113-118 y 122-124; Villoro Toranzo (1989), pp. 87-91; Viehweg (1991), p. 23; GARCía MÁynez (1985), pp. 120-123; NuñEz EnCabo (1979), pp. 177-178; QuintANA (1979), pp. 111-112 y 131-137; Atienza (1985), p. 291; Kaufmann y Hassemer (1992), pp. 93-94; y Zuleta Pucceiro, Enrique. Teoría del Derecho. Una introducción crítica. Buenos Aires: Ediciones Depalma, 1987, pp. 12-13.

63 En la jerga jurídica contemporánea se utiliza más el término Rechstlehre o Teoría del Derecho. En este sentido véase Rodríguez Molinero (1991), pp. 138-139; y Robles (1988), pp. 155-156. No obstante, pueden utilizarse también como sinónimos en el lenguaje jurídico contemporáneo, los términos Teoría General del Derecho y Teoría Fundamental del Derecho. Históricamente se ha empleado también la expresión Doctrina General del Derecho.

64 FERnÁNDEZ, p. 415.

65 El mismo autor agrega a continuación que “... Si las normas de las que parten abarcan la totalidad de los ordenamientos jurídicos, la teoría será general; si, por el contrario, sólo se refieren a un sector determinado de normas, será particular". Nuñez ENCABO (1979), p. 180.

66 Torré (1999), p. 85.

67 Pacheco (1993), p. 704.

68 El profesor Piovani es citado en NuÑEZ EnCABo (1979), p. 176.
} 
conceptuar esta disciplina como una "investigación científica que apunta a la elaboración de conceptos supremos que obran como principios reguladores de un determinado ordenamiento jurídico o de un cuerpo de ordenamientos"69.

Nosotros consideramos, que la Teoría del Derecho es una rama de la Filosofía del Derecho que estudia los elementos, estructuras y conceptos jurídicos comunes a todo ordenamiento jurídico, con un nivel teórico, de abstracción y generalidad superior al de la Dogmática Jurídica.

La perspectiva de estudio de la Teoría del Derecho se centra en los elementos, estructuras y conceptos jurídicos comunes a todo ordenamiento jurídico, que lo distinguen de otras pautas de conducta humana ${ }^{70}$.

A diferencia de la Dogmática Jurídica, la Teoría del Derecho es universal o general, ya que estudia los elementos comunes a todo ordenamiento jurídico avanzado, siendo sus reflexiones válidas en todos ellos ${ }^{71}$.

En opinión de variados autores, la principal diferencia entre Filosofía y Teoría del Derecho se halla precisamente en el objeto formal de estudio. Ello debido a que la Filosofía Jurídica se abocaría con mayor ímpetu a temas sustantivos del Derecho, mientras que la Teoría General del Derecho se centraría más en aspectos adjetivos, formales y estructurales presentes en el mismo ${ }^{72}$.

Otros estudiosos nos explican, como el objeto formal de la Teoría Jurídica, dirigido a los factores formales y abstractos del Derecho, marca también una distancia fundamental con las diversas ciencias jurídicas, interesadas en aspectos de fondo, que en el caso puntual de la Dogmática es el contenido del Derecho positivo interno ${ }^{73}$.

En todo caso, el profesor Miguel Villoro Toranzo considera que los contenidos de las normas jurídicas también forman parte del objeto formal de la Teoría

\footnotetext{
69 Williams, parte II p. 109.

70 En la jerga jurídica contemporánea se utiliza más el término Rechstlebre o Teoría del Derecho. En este sentido véase Rodríguez Molinero (1991), pp. 138-139; y Robles (1988), pp. 155-156. No obstante, pueden utilizarse también como sinónimos en el lenguaje jurídico contemporáneo, los términos Teoría General del Derecho y Teoría Fundamental del Derecho. Históricamente se ha empleado también la expresión Doctrina General del Derecho.

71 Sobre el carácter general de la Teoría del Derecho véase VilLoro Toranzo (1989), pp. 7, 10, 12 y 79; Finch (1977), p. 12; Nuñez Encabo (1979), p. 179; y Torré (1999), p. 87; Atienza (1985), p. 291; Fernández, p. 415; y Ara Pinilla (1996), p. 527. También Gregorio Robles señala esta cualidad como restrictiva de la Teoría General del Derecho que para él difiere de la Teoría del Derecho a secas. Véase sobre el tema Robles (1988), p. 156.

72 Sobre el objeto formal de la Teoría del Derecho véase Kaufmann y Hassemer (1992), p. 36; Villoro Toranzo (1989), pp. 7, 10 y 12; Viehweg (1991), p. 25; Durán, Paloma. Notas de Teoría del Derecho. Publicaciones de la Universidad Jaime I, 1997, p. 145; y FERNÁNDEZ, p. 407.

73 Véase la opinión de Giuseppe Lumia, citada en VilLoro Toranzo (1989), p. 10. También es ilustrativo el punto de vista de MAnuel Atienza al señalar que “... la teoría general del Derecho, salvo intentos que no tuvieron mucho éxito, como el de PAsukanis, se ha configurado como una teoría formal y abstracta del Derecho, en la medida en que no se interesa por los contenidos del Derecho -objeto de las dogmáticas jurídicas-, pero tampoco por la evolución histórica de esas formas, por sus condicionamientos sociales y políticos". ATIENZA (1985), pp. 291-292.
} 
del Derecho, siempre y cuando posean un carácter suficientemente general ${ }^{74}$. Posición que consideramos acertada, ya que explica la existencia de las denominadas "teorías generales" para cada rama específica del Derecho.

La Teoría del Derecho utiliza también el método comparativo o comparatis$\mathrm{ta}^{75}$, ya que el cotejo de los diversos ordenamientos positivos permite a continuación -mediante un proceso de abstracción- elaborar teorías generales que precisamente intentan extraer los elementos, estructuras y conceptos jurídicos fundamentales presentes en todos ellos.

Solo es posible una Teoría Jurídica si las fuentes jurídicas son reorganizadas, ordenadas y armonizadas unas con otras en el nivel interno, como asimismo entre los distintos ordenamientos ${ }^{76}$, lo que posteriormente permite al teórico del Derecho abstraerse de los elementos jurídicos particulares, para luego descubrir los principios y, estructuras comunes a todo ordenamiento normativo desarrollado, y finalmente, elaborar los conceptos jurídicos básicos.

La construcción de una Teoría General requiere de un análisis comparativo sobre las estructuras y factores comunes a los diversos ordenamientos jurídicos civilizados, que una vez determinados permiten la elaboración de conceptos básicos del Derecho, como el de norma jurídica o fuentes del Derecho, responsabilidad, derecho subjetivo, delito, etc.

\section{Relaciones entre Teoría del Derecho, Filosofía Jurí- dica y Ciencia del Derecho}

Con respecto a las relaciones entre Teoría General del Derecho, Filosofía Jurídica y Ciencia del Derecho, se han suscitado fundamentalmente dos posiciones. La primera considera a la Teoría del Derecho como parcela de la Filosofía Jurídica concebida en sentido lato, mientras que una segunda estima que ella se ubica más bien en el seno de la Ciencia General del Derecho.

\section{A. Teoría del Derecho como parcela de la Filosofía Jurídica}

Una primera corriente, representada por numerosos estudiosos ${ }^{77}$, concibe a la Teoría del Derecho como un conocimiento eminentemente filosófico, y, en tanto normativo, más bien perteneciente a la Filosofía del Derecho.

\footnotetext{
74 "Mi punto de vista es que también los contenidos de las normas jurídicas constituyen objeto de estudio de la TGD con tal que posean suficiente generalidad o en varios Derechos históricos o en varias ramas de un mismo Derecho histórico". Villoro Toranzo (1989), p. 10, reiterando la idea en p. 12.

75 En tal sentido véase Atienza (1985), p. 291; Villoro Toranzo (1989), p. 89; Fernández, p. 414; y Díaz (1992), p. 73.

76 Sobre ese punto véase NuÑEZ EnCabo (1979), p. 178.

77 En esta postura véase Kaufmann y Hassemer (1992), pp. 34-36; Ara Pinilla (1996), p. 527; Villoro Toranzo (1989), p. 7; Viehweg (1991), p. 25; Zuleta Pucceiro (1987), pp. 12-13; y Segura Ortega (2008), pp. 45-46.
} 
Sistematizando este grupo de opiniones, la Teoría del Derecho vendría a ser un sector de la Filosofía Jurídica considerada en sentido lato, existiendo una leve distinción de género a especie entre ambos saberes a partir de dos criterios: uno de carácter histórico, y el otro referido al objeto formal de estudio presente en dichas formas de conocimiento ${ }^{78}$.

\section{A.1. Criterio histórico}

Este parámetro de distinción puede sintetizarse a su vez en dos puntos: Primero, el fenómeno de emancipación de las ciencias particulares desde el interior de la Filosofía, y luego, el similar proceso de independencia de la Teoría Jurídica, desde el seno de la Filosofía del Derecho.

1. Las Ciencias emigran de la Filosofia: Si recurrimos a la historia del saber científico, observaremos que desde la Antigüedad todas las ciencias empíricas han tenido su origen en la Filosofía, y durante la modernidad han emigrado, haciéndose mundanas ya que han buscado algo práctico siendo auto expulsadas de la Filosofía ${ }^{79}$.

Los inicios de esta independencia continúan en la Baja Edad Media a través de tres disciplinas: la Teología, el Derecho y la Medicina, que en un proceso ligado a la aparición de las Universidades, claramente se van emancipando de la Filosofía.

Pero es probablemente a partir de la Edad Moderna donde se puede apreciar más nítidamente el fenómeno en comento, época en que las ciencias particulares habrían ido adquiriendo un desarrollo y autonomía cada vez mayor. Durante los siglos XVI, XVII y XVIII emigran de la Filosofía las ciencias formales (Matemática, Lógica Formal, etc.) y naturales (Física, Química, Biología, etc.). En el siglo XIX se han emancipado de la Filosofía las denominadas ciencias sociales, como la Psicología, a través de Sigmund Freud (1856-1939); la Sociología, con E. Saint-Simon (1760-1825), August Comte y Herbert Spencer (1820-1903); y la Antropología propiamente tal o cultural, con Claude LéviStrauss y Malinosky. Sin olvidar la Economía Empírica o Positiva, que emerge a finales del siglo XVIII con Adam Smith.

Con mayor antelación que las demás ciencias humanas, el Derecho y la Ciencia Histórica también se han ido independizando de la Filosofía. En efecto,

\footnotetext{
78 Sobre los dos criterios de distinción posibles entre Filosofía Jurídica y Teoría General del Derecho, seguiremos principalmente el orden de autores y reflexiones desarrolladas en KAUFMANN y HASSEMER (1992), pp. 34-36.

79 Sobre el proceso de emancipación de las ciencias desde el seno de la filosofía, véase HeIDEGGER, Martin. Einführung in die Metaphysik, Max Niemeyer Verlag, Tübingen, 1958; Introducción a la Metafísica. Ackermann PILÁri, Ángela (Trad.). $3^{\text {a Edi- }}$ ción. Barcelona: Editorial Gedisa, 1997, p. 20; y Heidegger, Martin. Zur Zache des Denkens, pp. 61-63, citado en KaufmanN y Hassemer (1992), p. 35.
} 
la Historiografía tiene sus reminicencias en la Historia literaria de Heródoto (484-425 a.C) y luego en la Historia pragmática de Tucídides (460-396 a.C.) y Polibio (208-126 a.C.). La Historiografía propiamente tal, o Historia en sentido científico, surge en el iluminismo del siglo XVIII como Filosofía de la Historia con Voltaire (1694-1778) y más exactamente con el padre Enrique Flórez en su Clave Historial ${ }^{80}$.

Por su parte, la Ciencia Jurídica en sentido estricto, exhibe sus primeras manifestaciones en la antigüedad con los juristas romanos del período clásico y postclásico, y más recientemente en el bajo medioevo y el renacimiento, con los glosadores y postglosadores, respectivamente.

De modo que la Filosofía representa el fundamento de las diversas ciencias particulares, si bien todas ellas constituyen hoy, disciplinas autónomas e independientes de aquel saber.

2. La Teoría General del Derecho se emancipa de la Filosofía Jurídica. Al proceso de emancipación de disciplinas desde la propia Filosofía, habría sucedido también un fenómeno similar, en virtud del cual determinadas materias propias de la Filosofía Jurídica se habrían ido distanciando de ella para conformar lo que hoy se denomina Teoría del Derecho; pero, teniendo en cuenta una gran diferencia, puesto que todos estos sectores representan en último término materias abordadas desde una perspectiva de naturaleza iusfilosófica, vale decir, que no han alcanzado aún el grado de autonomía necesario para considerarlas como ciencias independientes de la Filosofía Jurídica.

Según Hans Ryffel ${ }^{81}$, también se han separado de la Filosofía del Derecho diversas materias que antaño le pertenecieran. Ello se puede apreciar con los escritos de Immanuel Kant, George Friedrich Hegel y el mismo Gustav Radbruch, que versan tanto sobre temas de Filosofía Jurídica como de Teoría General del Derecho.

En esta misma línea Arthur Kaufmann sostiene que a lo largo de los últimos cuarenta años y debido al proceso de complejidad y especialización del saber, determinados temas propios de la Filosofía del Derecho se han independizado hasta cierto grado conformando lo que se ha denominado Teoría General del Derecho, no existiendo sin embargo, un límite claro entre ambos conocimientos, ya que todos los problemas que forman parte de la Teoría del Derecho

80 Sobre el origen y concepto de la Historiografía véase Bascuñán Valdés, Aníbal. Historia del Derecho. Tomo I. Apuntes en mimeógrafo de su curso profesado en la Escuela de Derecho de la Universidad de Chile. Santiago: Editorial Universitaria, 1951, pp. 237-241; y Eyzaguirre, Jaime. Historia del Derecho. 12ª Edición. Santiago: Editorial Universitaria, 1992, p. 9. 81 Ryffel, Hans. Grundprobbleme der Rechts- und Staadtsphilosophie; Philosophische Antropologie des Politischen, pp. 5, 19 y 32ss., citado en Kaufmann y Hassemer (1992), p. 35. 
constituyen auténticamente cuestiones iusfilosóficas, siendo esta disciplina una parcela de la Filosofía del Derecho en sentido genérico ${ }^{82}$.

\section{A.2. Diverso objeto formal}

Probablemente el principal criterio de distinción entre Filosofía y Teoría del Derecho, para quienes reconocen una relación de género a especie entre ambos saberes, sea la consideración de la perspectiva sobre la cual se aborda el análisis del fenómeno jurídico.

En este sentido, y siendo ambos estudios de naturaleza filosófica, en cuanto a su actitud cognoscitiva radical, presentarían entre si diversos enfoques de análisis sobre un mismo objeto jurídico. La Filosofía Jurídica strictu sensu apuntaría más bien al estudio de fenómenos materiales, mientras que la Teoría del Derecho incursionaría en aspectos más formales y estructurales del Derecho. En todo caso se trataría de una distinción muy tenue, porque ambas se caracterizan por la tendencia abarcante y general de su objeto formal, así como por la inclusión de aspectos de fondo, pero en distintos grados de intensidad.

El profesor Theodor Viehweg estima que la ubicación correcta de la Teoría General del Derecho tiene lugar en el seno de la Filosofía Jurídica, a la cual integra. Constituye entonces una Filosofía del Derecho en sentido objetivo, puesto que una y otra investigación coinciden en un cuestionar radical, ilimitado y general del Derecho ${ }^{83}$. En semejante posición para Ulrich Schroth no hay verdaderamente una distinta naturaleza entre Filosofía y Teoría Jurídica, puesto que ambas poseen una misma actitud, objeto, y problema de estudio ${ }^{84}$.

Ahora bien, según afirma Miguel Villoro Toranzo, la diferencia entre Filosofía Jurídica y Teoría General del Derecho no es de objeto material o contenido de estudio, ya que ambos saberes se aplican al Derecho en su integridad. La distinción se da en razón del objeto formal o perspectiva bajo la cual se considera el objeto material. La primera -como toda filosofía- plantea la investigación

\footnotetext{
82 "A lo largo del tiempo, y debido a la complicación progresiva de los diversos campos científicos que hacía inabarcable el conjunto de la ciencia, ha sucedido también que determinados temas de la filosofía del derecho se han separado, en los últimos tres o cuatro decenios, tratándose de ellos desde entonces bajo la denominación de 'Teoría del Derecho'. Así, por ejemplo, la teoría de las normas, la teoría de la legislación, la teoría del lenguaje jurídico, la teoría de la ciencia, la epistemología, la teoría de la argumentación y la teoría de la decisión jurídica, también lo relativo a la teoría del método jurídico, la semántica y la hermenéutica, la tópica y la retórica jurídicas, y algunas otras más”. KAufMann y Hassemer (1992), p. 36. 83 “... quisiera sostener la tesis de que ella misma es filosofía del derecho en sentido objetivo, a pesar de que ella misma no quisiera llamarse así. Pues si se parte de la concepción generalmente aceptada según la cual investigación filosófica (investigatio philosophica) es aquella que no sólo permite sino que exige el cuestionar ilimitado y radical, se constatará que la corriente a la que acabo de referirme pretende justamente esto. Desea, en su campo de problemas, cuestionar radicalmente, es decir, filosóficamente. No desea preguntar dentro de los límites (para otros fines, razonables) de una investigación especializada, por ejemplo, de la historia del derecho francés medieval, y tampoco dentro de los límites (igualmente razonables para otros fines) de una dogmática jurídica. Más bien, en su intención, coincide con toda investigación filosófica. Tampoco el camino que recorre en su trabajo se distingue básicamente del que en la actualidad es elegido por la mayoría de los filósofos". VIEHWEG (1991), p. 25.

84 Sсhroth, Ulrich. Was ist und was soll Rechtstheorie?, p. 1 y ss., citado en Kaufmann y Hassemer (1992), p. 34.
} 
del Derecho en el nivel de las causas últimas. La Teoría del Derecho es mucho menos ambiciosa y se acerca a las causas próximas ${ }^{85}$.

Siguiendo esa misma línea, para el profesor Arthur Kaufmann la Teoría Fundamental del Derecho se ocuparía mayoritariamente de aspectos formales y estructurales; mientras que la Filosofía Jurídica en sentido estricto, esto es, sin considerar a la Teoría General del Derecho, se encargaría más bien de los contenidos materiales, es decir, de aspectos de fondo. Sin embargo, el mismo autor considera que no es posible hacer una separación tajante entre ambos saberes; al menos no como aquella existente entre Filosofía del Derecho y Dogmática Jurídica. La Teoría del Derecho contemporánea, constituiría entonces la Filosofía Jurídica del postpositivismo ${ }^{86}$.

\section{B. Teoría del Derecho como rama de la Ciencia Jurídica}

Una segunda posición, encabezada por los gestores iniciales de la disciplina, como asimismo, por otros juristas contemporáneos ${ }^{87}$; considera los estudios de Teoría del Derecho como una rama o parcela de la Ciencia Jurídica.

Para sustentar esta tesis se suele recurrir también a un criterio histórico, referido al origen inmediato de la disciplina en cuestión. Precisamente, los inicios de la Teoría del Derecho se encuentran íntimamente ligados con la historia del formalismo jurídico, del positivismo jurídico y de la Ciencia Sistemática del Derecho. En efecto, la Teoría General del Derecho surge como una disciplina destinada a separar la Filosofía Jurídica de la Ciencia del Derecho, erradicando de esta última los elementos iusfilosóficos, axiológicos, y, en general metajurídicos presentes en la primera.

De esta forma, si se tiene en cuenta que la Teoría del Derecho se originó en

\footnotetext{
85 "La diferencia entre Filosofía del Derecho y TGD no es de objeto material de estudio; ambas se aplican al Derecho en su integridad. La diferencia se da en el objeto formal de estudio o perspectiva bajo la cual se considera el objeto material. La filosofía se interesa por la realidad última (ontología) del Derecho y quiere saber cómo esa realidad última se relaciona con el ser humano y afecta o debe afectar su desarrollo. La filosofía del Derecho -como toda filosofía- plantea la investigación del Derecho en el nivel de las causas últimas; quiere entender la universalidad de los seres y el lugar que ocupa el Derecho entre ellos. La TGD es mucho menos ambiciosa y se acerca a las causas próximas; ciertamente se quiere en contacto directo con el Derecho positivo pero se distancia un tanto de él para contemplar el orden racional latente en la globalidad de los Derechos positivos". Villoro Toranzo (1989), p. 7.

86 "Pero a diferencia de lo que ha sucedido, por ejemplo, con el derecho hereditario, el derecho penal, el derecho público y también con la sociología jurídica, que son disciplinas que se han independizado considerablemente, los ámbitos problemáticos que acabamos de mencionar como pertenecientes a la 'teoría del derecho' siguen siendo también parcelas de la filosofía del derecho, no existiendo hasta el momento criterio alguno que permita delimitar la teoría del derecho de la filosofía del derecho; todo lo más se puede establecer una cierta orientación aproximativa en este tema diciendo que la teoría del derecho se ocuparía más de los aspectos formales y estructurales mientras que la filosofía del derecho en sentido estricto o restringido se encargaría más de los contenidos materiales". KAUfmann y Hassemer (1992), p. 36.

87 Véase por ejemplo, Robles (1988), p. 156; Díaz (1992), pp. 73-79; Fernández, pp. 412 y 414; Brufaw Prats, Jaime. Teoría Fundamental del Derecho. $3^{a}$ Edición corregida y aumentada. Madrid: Editorial Tecnos, 1987, p. 329; Durán (1997), p. 35; ReAle (1982), pp. 237 y 243-244; NuÑEZ EnCABo (1979), pp. 164 y 179; WiLliams, parte II, pp. 101-102; у ATIENZA (1985), p. 292.
} 
el interior del empirismo lógico, del positivismo jurídico y de la Dogmática Jurídica del Círculo de Viena, parece bastante más razonable, en opinión de algunos juristas, considerarla como una parcela de la Ciencia del Derecho.

En el caso del jurista italiano Norberto Bobbio, la Teoría Fundamental del Derecho no es una disciplina filosófica, sino la búsqueda de las estructuras formales de la Ciencia Jurídica ${ }^{88}$. También para el profesor Elías Díaz, la Teoría del Derecho es una disciplina perteneciente a la Ciencia Jurídica, pero ubicada en un estrato superior al de la Dogmática debido a su mayor grado de abstracción y generalidad ${ }^{89}$.

En opinión de Gregorio Robles, y adoptando en este sentido una postura mixta, se hace necesario distinguir entre Teoría General del Derecho y Teoría del Derecho. Por Teoría General del Derecho, el autor entiende aquella disciplina surgida en el marco del positivismo jurídico -Allgemeine Rechtslehre-, que constituye el sector más general de las partes generales de la Sistemática Jurídica, perteneciendo, en consecuencia, a la Ciencia del Derecho. Por su parte, la Teoría del Derecho implica el análisis del lenguaje por los juristas y en similar posición que Arthur Kaufmann, la considera como la Filosofía Jurídica del postpositivismo ${ }^{90}$, con lo cual integra a la Filosofía del Derecho en sentido amplio, siendo un concepto histórico al igual que la Doctrina del Derecho Natural y la Filosofía del Derecho ${ }^{91}$.

\section{CONCLUSIONES DE LA INVESTIGACIÓN}

A modo de síntesis sobre los conceptos analizados en los distintos capítulos de esta obra, se pueden mencionar las siguientes conclusiones panorámicas.

\section{A. Además de la Jurisprudencia existen otros saberes referidos al FENÓMENO JURÍDICO}

Existe una verdadera gradación del saber jurídico. El Derecho se puede estudiar con un elevado nivel de abstracción e integración de la experiencia normativa, a través de la Filosofía Jurídica.

\footnotetext{
88 Véase la explicación de Lorca Navarrete, José María. Introducción al Derecho. Fundamentos filosóficos. Tomo I, Madrid: Ediciones Pirámide, 1987, p. 85.

89 Véase Díaz (1992), p. 73. Así mismo puede consultarse Williams, Jaime, parte II, pp. 101-102.

90 Véase Kaufmann y Hassemer (1992), p. 20

91 “...la Teoría del Derecho no es identificable con la Filosofía del Derecho en sentido estricto, ni tampoco con la doctrina del Derecho natural, pero si puede ser calificada como una forma de filosofía del Derecho en sentido amplio, concretamente aquella forma que se orienta por el modelo epistemológico del análisis del lenguaje. Tampoco puede confundirse con la 'Teoría General del Derecho', que constituye una disciplina de caracteres muy específicos (es la parte más general de las partes generales de la Dogmática jurídica) surgida en el marco del positivismo jurídico...”. RoBLEs (1988), p. 156. El profesor Rodríguez Molinero también comparte esta diferenciación. Sobre esto véase RodríGUEz MoLINERo (1991), pp. $138-140$.
} 
También es posible abordar el fenómeno jurídico integrando los datos de la experiencia desde la perspectiva de las ciencias sociales, estrato intermedio representado por la Jurisprudencia o Ciencia del Derecho.

Finalmente, encontramos un nivel sumamente práctico, de mínima integración de los datos aportados por la experiencia normativa. Se trataría de un saber jurídico de acción encomendado a la Técnica Jurídica.

La enseñanza del Derecho puede acercarse a cualquiera de estos tres niveles. La Filosofía Jurídica y la Jurisprudencia permiten comprender el Derecho, mientras que la Técnica Jurídica posibilita ejecutarlo. Es la diferencia entre la jurisprudencia como saber (filosófico o científico) y la jurisprudencia como profesión.

\section{B. Antes que ciencia jurídica la Filosofía del Derecho es un saber FILOSÓFICO}

De los diversos conceptos aproximados de la Filosofía del Derecho que hemos mencionado, emana una importante conclusión gnoseológica, distintiva de esta forma de conocimiento jurídico.

En efecto, estimamos que antes que una rama de las Ciencia Jurídicas, el análisis filosófico sobre el Derecho constituye una manifestación propia de la Filosofía. En estricto rigor no se trata de una disciplina jurídica porque no posee un método propio, sino tan solo un objeto formal indeterminado y abarcante. En este sentido la Filosofía Jurídica no pertenece a la Ciencia del Derecho sino a la Filosofía 92 .

\section{LAS SEPARACIONES ENTRE LAS DISTINTAS DISCIPLINAS QUE ESTUdIAN EL Derecho, No SON DEL TODO TAJANTES}

Hay casos como el de la Teoría del Derecho, que no se encasillan completamente en una u otra disciplina, y más bien se desenvuelven en un nivel intermedio, compartiendo rasgos de la Filosofía Jurídica y de la Ciencia del Derecho.

Otro grupo sumido en esta situación lo representan algunas disciplinas como la Historia, Sociología, Psicología y Antropología Jurídicas, que también se baten entre la Ciencia Jurídica y otras ciencias sociales.

\footnotetext{
92 En el mismo sentido el profesor López de OÑATE señala expresamente que "La filosofía del derecho es de naturaleza genuina e íntimamente filosófica". López de Oñate, Flavio. Filosofía del Derecho. Bianchi, Alberto S. (Trad.). Volumen I. Buenos Aires: Ediciones Jurídicas Europa-América, 1961, p. 18, reiterando la idea en pp. 27, 30 y 38 . En apoyo de dicha posición puede consultarse también VECCHIO (1991), p. 275; García MáYnez, Eduardo. Introducción al Estudio del Derecho.

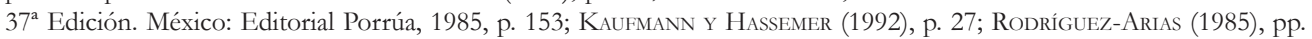
124-125; Tamayo y Salmorán (1984), p. 139; Fernández-Galiano, Antonio. Introducción Filosófica al Derecho. $2^{\mathrm{a}}$ Edición. Madrid: Editorial Ceura, 1977, pp. 49 y 60; Fernández, p. 420; Villoro Toranzo (1989), p. 7; Torré (1999), p. 66; STERNBerg, p. 186; y SQuella, Agustín. Filosofía del Derecho. Santiago: Editorial Jurídica de Chile, 2001, p. 143.
} 
D. Tampoco las Ciencias del Derecho se reducen a la Dogmática, sino QUE ABARCAN MUCHO MÁS

La Jurisprudencia, o mejor dicho, las Ciencias Jurídicas, se componen de variadas disciplinas que investigan el fenómeno jurídico desde diversos ángulos. Encontramos entonces tres grupos de ciencias jurídicas: puras, derivadas e incluso otras más. En el primer grupo destacan la Dogmática y la Ciencia del Derecho Comparado, y en el segundo la Historiografía Jurídica, la Sociología del Derecho, la Psicología Jurídica y la Antropología Jurídica. Lo anterior, sin perjuicio de que, según ciertos autores, algunas de ellas no pertenecen a la Ciencia del Derecho, sino más bien a otras ciencias sociales.

\section{E. La Filosofía del Derecho, la Dogmática Jurídica y la Teoría del DERECHO, CUMPLEN IMPORTANTES FUNCIONES PARA EL CONOCIMIENTO Y LA PRAXIS JURÍDICA}

Por último, para cerrar el listado de conclusiones, resulta necesario extraer consecuencias concretas, en cuanto resultados metodológicos o de carácter material asociados a cada una de las disciplinas que hemos abordado en el presente ensayo, esto es, Filosofía del Derecho, Dogmática Jurídica y Teoría del Derecho.

1. Aportes de la Filosofía del Derecho. La Filosofía Jurídica permite superar el enfoque tradicional del pensamiento iuspositivista que reduce la noción de Derecho al ordenamiento jurídico en vigencia; expandiendo la concepción sobre el fenómeno jurídico, de manera que incluya otras perspectivas, como su dimensión axiológica, histórica o cultural.

Asimismo, la Filosofía del Derecho permite ampliar la visión cognoscitiva del Derecho más allá de una simple técnica, rescatando su dimensión científica, y, por supuesto, filosófica ${ }^{93}$. En efecto, la teoría del conocimiento jurídico rebasa el estudio normativo estricto propio de la Ciencia Dogmática, intentando justamente un enfoque multidimensional del fenómeno jurídico.

Otra de los aportes de la Iusfilosofía en el campo del conocimiento se traduce en capacitar a la comunidad académica para el examen crítico de los fundamentos, contenidos y posibilidades de la propia Ciencia Jurídica, todo lo cual obedece a su actitud trascendente al sistema normativo.

La Filosofía Jurídica también posee una función de intermediación entre los

93 Una postura similar se aprecia en HüBnER GaLLo (1963), pp. 22-23. 
saberes y prácticas jurídicas, por una parte, y el resto de las prácticas y saberes sociales, incluyendo a la Filosofía, por otra ${ }^{94}$.

La Iusfilosofía constituye, por último, una herramienta teórica fundamental para las ramas de la Dogmática o Ciencia del Derecho positivo, sobre todo en el campo interpretativo y de la argumentación doctrinal. Este fenómeno se aprecia, por ejemplo, en la Ciencia del Derecho Constitucional, disciplina que constantemente recurre a factores filosóficos a la hora de conceptuar los valores superiores del ordenamiento jurídico recogidos por la Ley Fundamental ${ }^{95}$.

Así, las Cartas Constitucionales contemporáneas, incorporan frecuentemente conceptos axiológicos, como la dignidad humana, la igualdad o la libertad, considerados por la doctrina como valores superiores del ordenamiento jurídico interno. Tal concepción implica una actividad dogmática que reconoce la inclusión de pautas ético-jurídicas al interior de ciertos enunciados constitucionales que desbordan el análisis doctrinal estrictamente positivo, recurriendo a consideraciones axiológicas para explicar la naturaleza jurídica de tales valores constitucionales, línea en la cual se encuentra una parte importante de la Escuela Hermenéutica contemporánea ${ }^{96}$. Es el caso, por ejemplo, de nuestra Constitución.

Otra manifestación de los aportes teóricos de la Filosofía Jurídica para las ramas de la Ciencia Jurídica en sentido estricto, se puede observar en el campo de la Ciencia del Derecho Penal, atendido el protagonismo que adquieren los bienes jurídicos tutelados por dicho sector normativo, y que de un punto de vista jurídico proceden también del ordenamiento constitucional. También la denominada teoría de la pena se nutre de los aportes de la Filosofía en general y de la Filosofía Jurídica en particular. Incluso el proceso penal obedece a ella, ya que se exige la cita de los principios jurídicos sobre los cuales se dictó sentencia, con arreglo al artículo 342 literal "d" del Código Procesal Penal.

Otro tanto sucede con la equidad natural, reconocida por el ordenamiento civil y laboral como fuente supletoria destinada a la integración, interpretación y solución de antinomias para el Derecho positivo, que incluso goza en ciertos casos de aplicabilidad directa, todo lo cual supone una concepción iusfilosófica sobre el Derecho.

En efecto, los artículos 24 del Código Civil y $170 \mathrm{~N}^{\circ} 5$ del Código de Procedimiento Civil, $458 \mathrm{~N}^{\circ} 6$ del Código del Trabajo la recogen. Asimismo, el artícu-

\footnotetext{
94 Véase Atienza (1985), p. 371.

95 En similar posición, ABELARdo Torré nos dice que “... El científico del derecho, debe conocer los valores jurídicos positivos (o reales o relativos), para desempeñar con acierto su misión...” TorRé (1999), p. 71.

96 Véase, por ejemplo, Alexy, Robert. Teoría de los derechos fundamentales. Garzón Valdés, Ernesto (Trad.). Centro de Estudios Constitucionales, Madrid, 1993, pp. 141 y 147 y ss; y Alexy, Robert. El Concepto y la Validez del Derecho. SeÑa, Jorge M. (Trad.). Barcelona: Editorial Gedisa, 1994, p. 185.
} 
lo 1734 del Código Civil, a propósito del laudo emitido por el juez partidor de bienes. Por último, el artículo $640 \mathrm{~N}^{\circ} 4$ del Código de Procedimiento Civil la menciona como pauta de solución de arbitraje en que debe fundarse la sentencia de los amigables componedores.

2. Aportes de la Dogmática Jurídica. De los conceptos y caracteres analizados, cabe concluir que la comunidad dogmática realiza una función de transmisión del conocimiento sobre el Derecho positivo, que se concreta principalmente en el área académica por medio de las distintas cátedras impartidas en las universidades y la investigación dogmática concretada en publicaciones ${ }^{97}$.

Otro aporte cognoscitivo de la Ciencia Jurídico-Dogmática se materializa en la tarea de sistematización que por medio de teorías científicas reorganiza el Derecho Positivo, generalmente tratado en forma anárquica y desorganizada en los códigos ${ }^{98}$.

En síntesis, y debido a su carácter eminentemente práctico, la Sistemática permite comprender y aplicar mejor el Derecho positivo, colaborando en la solución de conflictos de relevancia jurídica.

Desde esta perspectiva, la argumentación doctrinal permite elaborar criterios hermenéuticos destinados a aplicar el Derecho positivo por parte de los juristas prácticos u operadores jurídicos ${ }^{99}$. Esa es, de un punto de vista práctico, la principal utilidad de los tratados, cursos, manuales y revistas especializadas que configuran la literatura dogmática.

Por otra parte, las argumentaciones dogmáticas permiten adaptar el ordenamiento jurídico a los cambios sociales, por una vía distinta de la reforma legislativa $^{100}$.

Esto se aprecia en la Ciencia del Derecho Procesal, que en materia de medios de prueba, ha incorporado en el concepto de documento del artículo 348 bis del Código de Procedimiento Civil diversos mecanismos tecnológicos, como cintas de audio y video, sin necesidad de modificar el articulado respectivo.

Por otra parte, la aludida función dogmática de mediación entre norma y realidad, genera un verdadero freno en la producción normativa, evitando recurrir a reformas legislativas con tanta frecuencia ${ }^{101}$.

En efecto, existen numerosas ocasiones en que la comunidad jurídica entrega

\footnotetext{
97 Véase también en este sentido Calsamiglia (1988), pp. 13, 130-132 y 145.

98 Sobre la labor sistemática desarrollada por la Ciencia Dogmática véase Torré (1999), pp. 54-55; y Nino (1991), pp. 333-334, y 338.

99 “Que los juristas realmente deduzcan proposiciones normativas a partir de principios o que simplemente 'arreglen' su doctrina en forma deductiva para 'reforzar' su validez, es un problema muy importante de la ideología de la jurisprudencia dogmática (y de la ciencia en general),...”. TAmayo y SALmorán (1984), p. 148.

100 Véase Calsamiglia (1988), p. 140.

101 Véase Calsamiglia (1988), p. 140.
} 
una interpretación que posibilita corregir una redacción legislativa deficiente, lo que permite prescindir de las enmiendas normativas. Esto lleva a los magistrados y funcionarios públicos a justificar con mayor acuciosidad sus fallos y dictámenes, sobre todo cuando se produce un cambio de línea en la jurisprudencia judicial y administrativa, ya que las opiniones doctrinales se van asentando en la práctica forense.

En la Dogmática civilista encontramos numerosas aplicaciones de este fenómeno. Así, por ejemplo, el artículo 647 del Código Civil, referido al estado de los frutos civiles percibidos, que debe entenderse desde que se pagan y no desde que se cobran, como dice el texto. También el artículo 998, del mismo cuerpo legal, alude al extranjero que fallece dentro o fuera de la república dejando bienes en Chile, siendo irrelevante jurídicamente la referencia al lugar donde el causante falleció.

Otro caso evidente acontece con el artículo 1438 del citado Código Civil, que al definir contrato o convención, confunde el objeto de la convención, el objeto del contrato y el objeto de la obligación, conceptos que la doctrina del ramo distingue claramente. A su vez, el artículo 1545 del mismo texto legal utiliza la expresión de invalidación del contrato, siendo que la que jurídicamente corresponde es la de resciliación.

Asimismo, se puede enunciar el artículo 39 de nuestra Carta Fundamental, que confunde los estados de excepción constitucional con las situaciones excepcionales que motivan su dictación, conceptos que la Dogmática constitucional ha distinguido nítidamente.

Una última expresión de las funciones ideológicas de la Sistemática consiste en la defensa explícita o implícita de valores jurídicos por parte de los juristas dogmáticos ${ }^{102}$. En efecto, la actividad Dogmática puede asumir la defensa de determinados valores y contenidos axiológicos al abordar el estudio de las instituciones y enunciados normativos, ya que a diferencia de lo que sostuvieron algunos pensadores iuspositivistas en los siglos XIX y XX, la denominada abdicación valorativa o neutralidad axiológica en el quehacer doctrinal no es un presupuesto esencial para la Dogmática Jurídica.

3. Aportes de la Teoría del Derecho. La Teoría Jurídica cumple una importante función cognoscitiva o de lege data, al elaborar una "teoría general" que permite introducir conceptualmente al jurista en las diversas ramas del Derecho positivo ${ }^{103}$. 
En segundo lugar, esta disciplina constituye un nexo de mediación entre la Filosofía del Derecho y la Dogmática Jurídica ${ }^{104}$.

La Teoría del Derecho también desarrolla una función de lege ferenda, ya que el estudio general y comparado de los ordenamientos jurídicos permite incorporar aquellas instituciones jurídicas que han resultado exitosas en otros Esta$\operatorname{dos}^{105}$.

Por último, esta disciplina jurídica contribuye, también como política jurídica de sententia ferenda, en lo que atañe a la aplicación e interpretación del Derecho, ya que ha desarrollado una nutrida teoría de la hermenéutica e integración jurídicas, así como de la argumentación, cuya presencia se hace indispensable para magistrados y litigantes, en el ámbito forense. 


\section{Bibliografía}

Aguilera, Bruno. Introducción Jurídica a la Historia del Derecho. $1^{\text {a }}$ Edición. Madrid: Editorial Cívitas, Madrid S.A., 1994.

Aftalión, Enrique; Vilanova, José y RafFo, Julio. Introducción al Derecho. $3^{\mathrm{a}}$ Edición. Buenos Aires: Editorial Abeledo-Perrot, 1988.

Alchourrón, Carlos y Bulygin, Eugenio. Introducción a la metodología de las ciencias jurídicas y sociales. $1^{\text {a }}$ Edición 1975. Buenos Aires: Editorial Astrea, $4^{\mathrm{a}}$ reimpresión 2002.

AlEXY, Robert. Teoría de los derechos fundamentales. Garzón VALDÉs, Ernesto (Trad.). Centro de Estudios Constitucionales, Madrid, 1993.

Alexy, Robert. El Concepto y la Validez del Derecho. SeÑA, Jorge M. (Trad.). Barcelona: Editorial Gedisa, 1994.

Almoguera, Joaquín. Lecciones de Teoría del Derecho. Madrid: Editorial Reus S.A., 1995.

Ara Pinilla, Ignacio. Teoría del Derecho. Madrid: Taller de Ediciones, J.B., 1996.

Arias Ramos, J. y Arias Bonet, J.A. Derecho Romano. 15 Edición. Madrid: Editorial Revista de Derecho Privado, 1976.

Atienza Rodríguez, Manuel. Introducción al Derecho. Barcelona: Editorial Barcanova, 1985.

Ávila Martel, Alamiro de. Derecho Romano. 2a Edición. Santiago: Editorial Jurídica de Chile, 2000.

Ballesteros Llompart, Jesús. Sobre el Sentido del Derecho, Introducción a la Filosofía Jurídica. $2^{\mathrm{a}}$ Edición 1986. Madrid: Editorial Tecnos, $2^{\mathrm{a}}$ reimpresión 1992.

Barrientos Grandon, Javier. Introducción a la Historia del Derecho Chileno. Santiago: Editorial Barrocos Libreros, 1994.

Barros Errázuriz, Alfredo. Curso de Derecho Civil. Primer Año. Santiago: Imprenta Chile, 1915.

Bascuñán Valdés, Aníbal. Historia del Derecho. Tomo I. Apuntes en mimeógrafo de su curso profesado en la Escuela de Derecho de la Universidad de Chile. Santiago: Editorial Universitaria, 1951.

BASCUÑÁN VALDÉs, Aníbal. Introducción al estudio de las Ciencias Jurídicas y Sociales. 2a Edición. Santiago: Editorial Jurídica de Chile, 1960.

Bascuñán Valdés, Aníbal. "Los Principios de la Ciencia General del Derecho". En Anuario de Filosofía Jurídica y Social. Sociedad Chilena de Filosofía Jurídica y Social, Santiago, 1989.

Betegón CARRILlo, Jerónimo. Lecciones de Teoría del Derecho. Madrid: Mc. Graw-Hill, Interamericana de espanan, 1997.

Bodenheimer, Edgar. Teoría del Derecho. México: Editorial Fondo de Cultura Económica, 1964.

Boвbio, Norberto. Teoría General del Derecho. Bogotá: Editorial Temis, 1987. Brieskorn, Norbert. Filosofia del Derecho. Curso Fundamental de Filosofía. Barcelona: Editorial Herder. 
Brufaw Prats, Jaime. Teoría Fundamental del Derecho. $3^{\text {a }}$ Edición corregida y aumentada. Madrid: Editorial Tecnos, 1987.

CAlsamiglia, Albert. Introducción a la Ciencia Jurídica. $2^{\text {a }}$ Edición. Barcelona: Editorial Ariel, 1988.

Cannata, Carlos Augusto. Historia de la Ciencia Jurídica Europea. Madrid: Editorial Tecnos, 1996.

CArpintero, Francisco. Una Introducción a la Ciencia Jurídica. $1^{\text {a }}$ Edición 1988. Madrid: Editorial Civitas, reimpresión 1989.

Corng, Helmut. Filosofía del Derecho. Barcelona: Editorial Ariel Barcelona, 1970.

CoIng, Helmut. Las tareas del historiador del Derecho. Sevilla: Publicaciones de la Universidad de Sevilla, 1977.

Corng, Helmut. Historia del Derecho Privado Europeo. Tomo I. Fundación Cultural del Notariado, Madrid, 1996.

Cossio, Carlos. La plenitud del ordenamiento jurídico. Buenos Aires: Editorial Losada, 1947.

De Lucas Martín, Javier. Introducción a la Teoría del Derecho. Valencia: Editorial Tirant lo Blanch, 1992.

De Lucas Martín, Javier; et al. Introducción a la Teoría del Derecho. $3^{\mathrm{a}}$ Edición. Madrid: Editorial Tirant lo Blanch, 1997.

DíAz, Elías. Sociología y Filosofía del Derecho. $2^{\mathrm{a}}$ Edición. Madrid: Editorial Taurus, 8 a reimpresión 1992.

D'ors, Álvaro. Una Introducción al Estudio del Derecho. $4^{\mathrm{a}}$ Edición. Valparaíso: Ediciones Universitarias de Valparaíso, 2003.

Durán, Paloma. Notas de Teoría del Derecho. Publicaciones de la Universidad Jaime I, 1997.

Engich, Karl. Filosofía del Derecho. Editorial Fondo de Cultura Económica.

ERrÁzUriz Mackenna, Carlos José. Introducción Crítica a la Doctrina Jurídica de Kelsen. Santiago: Editorial Jurídica de Chile, 1987.

Eyzaguirre, Jaime. Historia del Derecho. 12a Edición. Santiago: Editorial Universitaria, 1992.

Eyzaguirre, Jaime. Historia del Derecho. Apuntes de clases. Santiago: Editorial Universitaria, 1953.

Fernández-Galiano, Antonio. Introducción Filosófica al Derecho. $2^{\mathrm{a}}$ Edición. Madrid: Editorial Ceura, 1977.

FInch, John. Introducción a la Teoría del Derecho. LAPORTA SAN Miguel, Francisco (Trad.). Barcelona: Editorial Labor, 1977.

García Máynez, Eduardo. Introducción al Estudio del Derecho. $37^{\mathrm{a}}$ Edición. México: Editorial Porrúa, 1985.

GoldschmidT, Werner. Introducción filosófica al Derecho. Buenos Aires: Editorial Depalma, 1973.

Hamilton Depassier, Carlos. Manual de Historia del Derecho. Santiago: Editorial Jurídica de Chile, 1948.

Heidegger, Martin. Einführung in die Metaphysik, Max Niemeyer Verlag, Tübingen, 1958; Introducción a la Metafísica. ACKermanN PILÁRI, Ángela (Trad.). $3^{\text {a }}$ Edición. Barcelona: Editorial Gedisa, 1997. 
Henkel, Heinrich. Introducción a la Filosofía del Derecho. Madrid: Editorial Taurus, 1963.

Herrera Paulsen, Darío. Derecho Romano. $3^{\text {a }}$ Edición. Lima: Editorial y Distribuidora de Libros, 1988.

Hessen, Johanes. Teoría del Conocimiento. Gaos, José (Trad.). 25ª Edición. Buenos Aires: Editorial Losada, 1996.

Hübner Gallo, Jorge. Introducción al Derecho. $5^{\text {a }}$ Edición. Santiago: Editorial Jurídica de Chile, 1984.

Hübner Gallo, Jorge. Manual de Filosofía del Derecho. $2^{\text {a }}$ Edición. Santiago: Editorial Jurídica de Chile, 1963.

Iglesias, Juan. Derecho Romano. Historia e Instituciones. $10^{\text {a }}$ Edición. Barcelona: Editorial Ariel, 1990.

Iribarren Cabezas, Juan Antonio. Historia General del Derecho. Santiago: Editorial Nascimiento, 1938.

Kaufmann, Arthur y Hassemer, Winfried. El Pensamiento Jurídico Contemporáneo. Traducción al español de varios autores bajo la dirección de Robles Morchón, Gregorio. Madrid: Editorial Debate, 1992.

Kelsen, Hans. Teoría Pura del Derecho. Vernengo, Roberto J. (Trad.). $1^{a}$ Edición en español 1979. México: Editorial Porrúa, 1995.

Kelsen, Hans. Teoría General del Derecho y del Estado. Nueva York: Russel and Russel, 1960.

Kirchmann, Julius Herman von. La Jurisprudencia no es ciencia. Madrid: Editorial IEP, 1961.

Kunkel, Wolfgang. Historia del Derecho Romano. Miquel, Juan (Trad.). $9^{\mathrm{a}}$ Edición 1985. Barcelona: Editorial Ariel, 2ª reimpresión 1991.

Larenz, Karl. Metodología de la Ciencia del Derecho. $2^{\mathrm{a}}$ Edición. BarcelonaCaracas- México: Editorial Ariel, 2001.

LARENZ, Karl. La filosofía contemporánea del derecho y del estado. 1903.

LATORRE, Ángel. Introducción al Derecho. $6^{\mathrm{a}}$ Edición. Barcelona: Editorial Ariel, 1990.

LÉvy-BruHL, Henry. Sociología del Derecho. $2^{\text {a }}$ Edición. Buenos Aires: Editorial Eudeba, 1966.

López Calera, Nicolás. Introducción al Estudio del Derecho. Editorial Don Quijote: Los Libros del Bachiller Sansón Carrasco, 1981.

LóPez de Oñate, Flavio. Filosofia del Derecho. Bianchi, Alberto S. (Trad.). Buenos Aires: Ediciones Jurídicas Europa-América, 1961.

Lorca Navarrete, José. Introducción al Derecho. Fundamentos filosóficos. Tomo I. Madrid: Ediciones Pirámide, 1987.

Losano, Mario G. Los Grandes Sistemas Jurídicos. Ruiz Miguel, Alfonso (Trad.). Madrid: Editorial Debate, 1982.

Luhmann, Niklas. Sistema Jurídico y Dogmática Jurídica. De Otto Pardo, Ignacio (Trad.). Madrid: Centro de Estudios Constitucionales, 1983.

Lumia, Giuseppe. Principios de Teoría e Ideología del Derecho. Madrid: Editorial Debate, 14 reimpresión, 1993.

Malberg, Carré de. Teoría General del Estado. 1ª Edición en francés 1922. 
Lion Depetre, José (Trad.). $2^{\mathrm{a}}$ Edición en español 1998. México: Fondo de Cultura Económica, $1^{\mathrm{a}}$ reimpresión 2000.

Martínez Roldán, Luis. Curso de Teoría del Derecho y Metodología Jurídica.

Barcelona: Editorial Ariel Derecho, 1994.

Mendonca, Daniel y Guiborg, Ricardo. La odisea constitucional. Constitución, teoría y método. Madrid: Editorial Marcial Pons, 2004.

Merello, Ítalo. Historia del Derecho. Volumen I. $2^{\mathrm{a}}$ Edición 1989. Valparaíso: Ediciones Universitarias de Valparaíso, 1991.

Merryman, John Henry. La tradición jurídica romano canónica. SuÁrez, Luis L. (Trad.). 2a Edición corregida 1989. México: Editorial Fondo de Cultura Económica, $1^{\mathrm{a}}$ reimpresión 1993.

Millas, Jorge. Filosofia del Derecho. Santiago: Ediciones Publilex, 1970.

Millas, Jorge. Filosofía del Derecho. Apuntes en mimeógrafo de su curso profesado en la Escuela de Derecho de la Universidad de Chile, Santiago, 1953.

Muñoz Sabaté, Luis; et al. Introducción a la Psicología Jurídica. México: Editorial Trillas, 1980.

Nino, Carlos. Introducción al Análisis del Derecho. 4ª Edición. Barcelona: Editorial Ariel, 1991.

Nino, Carlos. Algunos Modelos Metodológicos de Ciencia Jurídica. $1^{\text {a }}$ Edición. México: Editorial Fontamara, 1993.

Nino, Carlos. Derecho Moral y Política. Barcelona: Editorial Ariel, 1994.

NuÑEz EnCABo, Manuel. Introducción al Estudio del Derecho. Madrid: Editorial Alambra, 1979.

Pacheco, Máximo. Teoría del Derecho. $4^{a}$ Edición 1990. Santiago: Editorial Jurídica de Chile, reimpresión 1993.

PACHeCo, Máximo. Introducción al Estudio de las Ciencias Jurídicas y Sociales. Santiago: Editorial Universitaria, 1952.

Palma GonzÁlez, Eric Eduardo. Historia del Derecho I. Introducción. Santiago: Universidad Central de Chile, 2001.

Pietro, Alfredo di. Manual de Derecho Romano. 4a Edición. Buenos Aires: Ediciones Depalma, 6 reimpresión 1996.

PRIETO, Luis. Introducción al Derecho. Cuenca: Ediciones de la Universidad de Castilla La Mancha, 1996.

Pizzorusso, Alessandro. Curso de Derecho Comparado. Bignozzi, Juana (Trad.). Barcelona: Editorial Ariel, 1987.

Quintana Bravo, Fernando. La Ciencia del Derecho. De la Modernidad a nuestros días. Santiago: Editorial Universitaria, 1979.

RADBRUCH, Gustav. Introducción a la Filosofia del Derecho. Roces, Wenceslao (Trad.). $1^{\text {a }}$ Edición en español. Buenos Aires: Editorial Fondo de Cultura Económica, $5^{\mathrm{a}}$ reimpresión 1993.

Reale, Miguel. Introducción al Derecho. $5^{\mathrm{a}}$ Edición. Madrid: Ediciones Pirámide, 1982.

Reale, Miguel. Filosofía del Derecho. Introducción Filosófica General. Madrid: Ediciones Pirámide, 1979.

Robles, Gregorio. Introducción a la Teoría del Derecho. Madrid: Editorial Debate, 1988. 
Rodríguez-Arias, Lino. Filosofia y Filosofía del Derecho. Bogotá: Editorial Temis Librería, 1985.

Rodríguez Molinero, Marcelino. Introducción a la Ciencia del Derecho.

Salamanca: Librería Cervantes, 1991.

Rodríguez Paniagua, José María. Historia del Pensamiento Jurídico. Tomos

I y II. $7^{\text {a }}$ Edición.. Universidad Complutense - Facultad de Derecho Sección de Publicaciones, Madrid, 1993.

Salvat Monquillot, Manuel y Ávila, Alamiro de. Historia del Derecho. Parte

I. Apuntes en mimeógrafo de su curso profesado en la Escuela de Derecho de la Universidad de Chile. Santiago, 1976.

SAmper, Francisco. Derecho Romano. $3^{\text {a }}$ Edición. Santiago: Ediciones Universidad Internacional SEK, 1993.

Savigny, Carlos de. De la vocación de nuestro siglo para la legislación y la ciencia del derecho. PosadA, Adolfo (Trad.). $1^{\text {a }}$ Edición. Valparaíso: Editorial Edeval, 1978.

Segura Ortega, Manuel. Lecciones de Teoría del Derecho. Editorial Universitaria Ramón Areces, 2008.

SQuella, Agustín. Introducción al Derecho. Santiago: Editorial Jurídica de Chile, 2000.

SQuella, Agustín. Filosofia del Derecho. Santiago: Editorial Jurídica de Chile, 2001.

Soriano, Ramón. Compendio de Teoría General del Derecho. 2a Edición corregida y aumentada. Barcelona: Editorial Ariel Derecho, 1993.

Sternberg, Theodor. Introducción a la Ciencia del Derecho. $2^{\mathrm{a}}$ Edición. Editorial Labor.

Tamayo y Salmorán, Rolando. El Derecho y la Ciencia del Derecho. Universidad Nacional Autónoma de México, México, 1984.

Topacio, Aldo. Historia del Derecho. Valparaíso: Editorial Edeval, 1996.

TORRÉ, Abelardo. Introducción al Derecho. $12^{\mathrm{a}}$ Edición. Buenos Aires: Editorial Abeledo-Perrot, 1999.

Vecchio, Giorgio del. Filosofía del Derecho. $9^{a}$ Edición revisada por Luiz Legaz y Lacambra, corregida y aumentada. Barcelona: Bosch Casa Editorial, 2a reimpresión 1991.

Vernengo, Roberto. Curso de Teoría General del Derecho. $2^{\text {a }}$ Edición. Buenos Aires: Ediciones Buenos Aires, 2a reimpresión 1986.

Vienweg, Theodor. Tópica y Jurisprudencia. Diez Picazo Ponce De León, Luis (Trad.). Madrid: Editorial Taurus, 1964.

Vienweg, Theodor. Tópica y Filosofía del Derecho. SeÑa, Jorge M. (Trad.). Madrid: Editorial Gedisa (1964), 1991.

Villey, Michel. Compendio de Filosofía de Derecho. Pamplona: Ediciones Universidad de Navarra, 1981.

Villoro Toranzo, Miguel. Teoría General del Derecho. México: Editorial Porrúa, 1989.

Vinogradoff, Paul. Introducción al Derecho. Herrero, Vicente (Trad.). $4^{a}$ Edición en español 1978. Santiago: Editorial Fondo de Cultura Económica, 1ª reimpresión 1994. 
Vives, Francisco. Filosofía del Derecho. $3^{\mathrm{a}}$ Edición. Santiago: Editorial Jurídica de Chile, 1957.

Williams, Jaime. Filosofía del Derecho. Parte I, II, III y IV. Apuntes en mimeógrafo de su curso profesado en la Escuela de Derecho de la Universidad de Chile, Santiago.

Zuleta Pucceiro, Enrique. Teoría del Derecho. Una introducción crítica. Buenos Aires: Ediciones Depalma, 1987.

ZweIgert, Honrad y KöTz, Hein. Introducción al Derecho Comparado. APARICIO VÁzQuez, Arturo (Trad.). Oxford University Press.

\section{DicCIONARIOS Y ENCICLOPEDIAS}

Abganano, Nicola. Diccionario de Filosofía. 2a Edición en español 1963.

México: Editorial Fondo de Cultura Económica, 10ª reimpresión 1993.

Brugger, Walter. Diccionario de Filosofía. 13 ${ }^{\mathrm{a}}$ Edición. Barcelona: Editorial Herder, 1993.

Capitant, Henri. Vocabulario Jurídico. Guaglianone, Aquiles Horacio (Trad.)

$1^{\text {a }}$ Edición. Buenos Aires: Ediciones Depalma, 8a reimpresión 1986.

Coromillas, J. y Pascual, J.A. Diccionario Crítico Etimológico Castellano e

Hispánico. Volumen CE-F. $1^{\mathrm{a}}$ Edición 1980. Madrid: Editorial Gredos, $2^{\text {a }}$ reimpresión 1987.

Couture, Eduardo. Vocabulario Jurídico. 1ª Edición 1976. Buenos Aires:

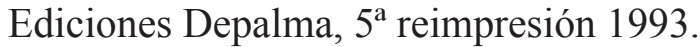

Enciclopedia Jurídica OmeBa. Tomo IX. Buenos Aires: Editorial Driskill, 1990.

Enciclopedia Universal Ilustrada Europeo-Americana. Tomo XVIII, N¹8

DEM-DIR (primera parte), $\mathrm{N}^{\circ} 18$ DIS-ECZ (segunda parte) y $\mathrm{N}^{\circ} 28$

INT-KZ. Madrid-Barcelona: Editorial Espasa Calpe, 1924.

EsCRICHE, Joaquín. Diccionario Razonado de Legislación y Jurisprudencia.

Tomo I y II. $1^{\text {a }}$ Edición. Santiago: Editorial Jurídica Conosur, reimpresión 1995.

Ferrater Mora, José. Diccionario de la Filosofía del Derecho. Volumen A-D y E-J. $1^{\text {a }}$ Edición. Barcelona: Editorial Ariel, 1994.

García Garrido, Manuel Jesús. Diccionario de Jurisprudencia Romana. $3^{\mathrm{a}}$ Edición. Madrid: Editorial Dykinson S.L., $2^{\mathrm{a}}$ reimpresión1993.

Real Academia Española. Diccionario de la Lengua Española. Volumen I y II. $21^{a}$ Edición. Madrid: Editorial Espasa Calpe, 1992.

RiBo Durán, Luis. Diccionario de Derecho. Barcelona: Bosch Casa Editorial, 1987. 